Boletín de la Sociedad Geológica Mexicana

Volumen Conmemorativo del Centenario

Grandes Fronteras Tectónicas de México

Toмo LVII, NÚM. 1, 2005, P. 1-26

\title{
La Megacizalla Mojave-Sonora: la hipótesis, la controversia y el estado actual de conocimiento
}

\author{
Roberto S. Molina-Garza* y Alexander Iriondo \\ Centro de Geociencias, Universidad Nacional Autónoma de México \\ Campus Juriquilla, Querétaro, 76230, México \\ *rmolina@geociencias.unam.mx
}

\begin{abstract}
Resumen
El modelo de la megacizalla Mojave-Sonora, el cual implica desplazamiento lateral izquierdo en el norte de México durante el Jurásico, permanece como una de las ideas más influyentes en la geología del país. Una revisión general de la literatura relacionada con el tema no permite aún resolver la controversia sobre la validez de la hipótesis, pero una conclusión clara es que la hipótesis original estaba basada en un modelo relativamente simplista de la geología de Sonora, ya que el basamento del terreno Caborca no es un simple fragmento de la corteza Mojave del este de California. Intentos de utilizar métodos cuantitativos han dado resultados contrarios a la hipótesis, como el de las rotaciones horarias indicadas por el paleomagnetismo y la diversidad de basamentos en Caborca que sugieren la geocronología y geoquímica; otros métodos producen resultados indeterminados, como la proveniencia de circones en las cuarcitas de la cobertura del terreno Caborca. La conclusión más relevante de esos estudios es la abundancia de circones de edad Grenvilleana, pero su presencia no puede simplemente atribuirse a fuentes en la Provincia Grenville en un modelo fijista. Las correlaciones estratigráficas entre secuencias Paleozoico tardío y Mesozoico en Caborca y secuencias similares en California y Nevada no producen argumentos convincentes a favor de grandes desplazamientos, pero deben considerarse con datos más detallados. Elementos que podrían evaluar la hipótesis con mayor contundencia son estudios más detallados del basamento, una estratigrafía fina del arco volcánico Jurásico y de las rocas volcanoclásticas al sur de la traza inferida de la falla y un mejor conocimiento de la secuencia miogeosinclinal. Son pocos los estudios estructurales en la región y en particular un problema importante es resolver en tiempo y espacio los efectos de la deformación compresional Cretácico-terciario. Un modelo que no entra en conflicto con la evidencia existente es la propuesta de que el desplazamiento del terreno parautóctono Caborca haya ocurrido en el Paleozoico tardío. Sin embargo, los datos existentes y las relaciones geológicas en la región de Caborca, no requieren de un desplazamiento de cientos de kilómetros en el Jurásico Tardío.
\end{abstract}

Palabras clave: Megacizalla Mojave-Sonora, terreno Caborca, noroeste de México, Proterozoico.

\section{Abstract}

The Mojave-Sonora megashear model, which implies left-lateral strike slip motion of northern Mexico in Jurassic time, remains as one of the most influential ideas in the geology of Mexico. A comprehensive review of the literature related to this topic does not yet allow to resolve the controversy over the validity of this hypothesis. A clear conclusion is that the original hypothesis was based on a relatively simplistic model of the geology of Sonora, as the basement of the Caborca terrane is not simply a fragment of the Mojave Precambrian basement Province of eastern California. Attempts to use quantitative techniques in testing the model have yielded results contrary to the hypothesis, such as clockwise rotations 
indicated by paleomagnetic data, and the diversity and complexity of the basement of Caborca indicated by geochemical and geochronological data. Other quantitative methods such as zircon provenance studies in quartzites of the sedimentary cover yield non-conclusive results. The main conclusion of the studies of detrital zircons is that Grenvillean zircons are relative abundant, but their presence cannot be attributed solely to sources in the Grenville Province in a fixist model. Stratigraphic correlations of upper Paleozoic and Mesozoic rocks in Caborca with similar sequences in California and Nevada do not provide convincing arguments of large displacement, but should be evaluated in more detail. Elements that have the potential to test the hypothesis with greater certainty include detailed studies of basement rocks, a refined stratigraphy of the Jurassic volcanic and volcaniclastic arc rocks south of the inferred fault trace, and better understanding of depositional trends in the miogeoclinal sequence. Structural studies are sparse in the region. In particular, is important to gain a better understanding of the effects in time and space of Late Cretaceous-Tertiary contractional deformation. A tectonic evolution model that does not conflict the existing data is the proposal that displacement of a parautochtonous Caborca terrane may have occurred in the Late Paleozoic. Nonetheless, available data and geologic relations in the Caborca region do not require Late Jurassic slip of several hundred kilometers.

Key words: Mojave-Sonora megashear, Caborca terrane, northwestern Mexico, Proterozoic.

\section{Introducción}

\subsection{La hipótesis}

La hipótesis de la megacizalla Mojave-Sonora (MMS) es una de las ideas que más han influido en el pensamiento geológico en México. Propuesta en los años setenta (Silver y Anderson, 1974), la hipótesis como se conoce hoy sugiere la existencia de un sistema de fallas de corrimiento lateral izquierdo, con orientación NW-SE, activo en el Jurásico Medio-Tardío y que se extiende desde el Desierto de Mojave en el este de California, en los Estados Unidos, cruzando el norte de México hasta unirse con una también hipotética dorsal en el Golfo de México (Anderson y Schmidt, 1983). La hipótesis original está basada en la observación de la aparente yuxtaposición de dos provincias de basamento Precámbrico de distinta edad e historia geológica en el noroeste de Sonora, en la región de Caborca ("This zone... disrupts two northeasterly-trending orogenic and magmatic belts of Precambrian age"; Anderson et al., 1979). Estas provincias en Sonora estaban, sin embargo, definidas con base en sólo seis localidades con determinaciones de edades U-Pb en circones (dos al norte de la MMS; Anderson y Silver, 1981; Figura 1).

El argumento original de la yuxtaposición de provincias de basamento Precámbrico es más complejo del inicialmente pensado. El basamento de la región noroeste de Sonora al sur de la traza hipotética de la MMS, perteneciente a las provincias Mojave y/o Yavapai es, en efecto, diferente al basamento expuesto en el noreste de Sonora, perteneciente a la provincia Mazatzal (Conway y Silver, 1989). Pero la edad del basamento de la región del NW de Sonora, y su afinidad, todavía no se conocen con suficiente detalle. No sólo porque los resultados analíticos del trabajo original (Silver y Anderson, 1974) no fueron publicados, sino también porque son pocos los estudios de este basamento. Los datos más recientes (Iriondo y Premo, 2003; Iriondo et al., 2004) indican que el basamento de la secuencia miogeosinclinal Precámbrico-Paleozoico de la región de Caborca es un basamento compuesto. El basamento en Sonora incluye elementos de la provincias Mojave y Yavapai y quizá de la zona de transición entre ambas provincias (Iriondo et al., 2004). Esta conclusión es sólida y se basa en edades de cristalización, edades modelo, geoquímica y relaciones isotópicas.

Los detalles de la edad de actividad de la MMS se definieron en la región de Caborca, en el NW de Sonora. Aquí se reconoció que la secuencia miogeosinclinal Neoproterozoico y Paleozoico inferior (Capas Gamuza y unidades sobreyacentes) se puede correlacionar, formación por formación, con la secuencia del este de California y el sur de Nevada, en las montañas Inyo y San Bernardino (Eells, 1972; Stewart et al., 1984; Stewart, 2003). La correlación de la secuencia de Caborca con la sección expuesta en el Desierto Mojave ha sido utilizada para estimar la magnitud de desplazamiento en la megacizalla, la cual es aproximadamente $800 \mathrm{~km}$. La edad aproximada de actividad de la falla está basada en la aparente yuxtaposición de rocas del Jurásico Medio al norte de la traza hipotética de la falla contra rocas de la secuencia miogeosinclinal al sur de la misma (Anderson y Silver, 1979).

\subsection{Significado geotectónico}

Desde su propuesta original, la megacizalla MojaveSonora (MMS) ha sido tema de controversia. Aún así, la hipótesis fue rápidamente adoptada por investigadores interesados en reconstrucciones paleogeográficas de la Pangea ecuatorial en el Paleozoico tardío ya que ofrece una elegante solución al problema del traslape entre América del Sur y gran parte de México al cerrar la región del Golfo 


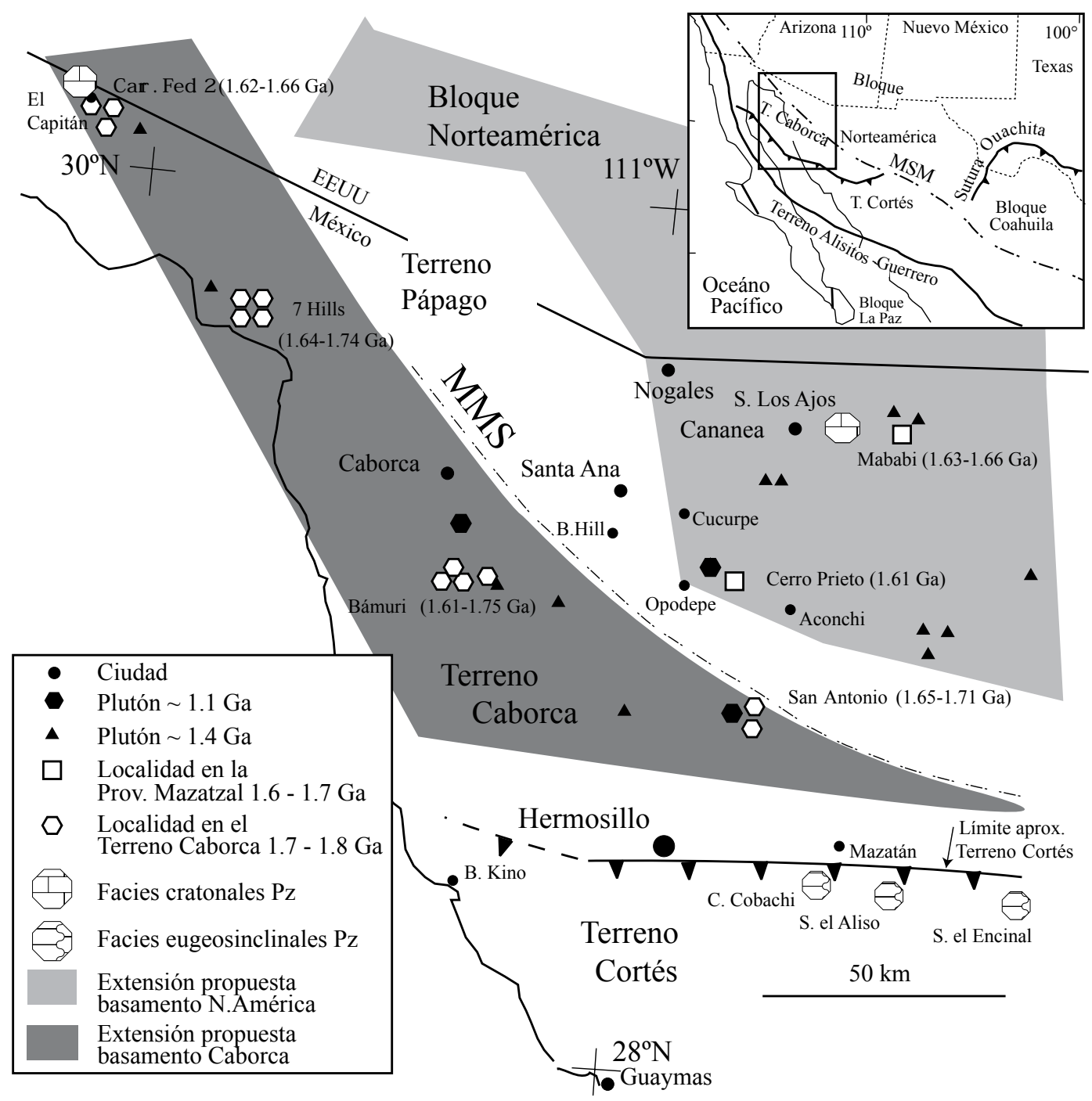

Figura 1. Provincias de basamento Precámbrico en Sonora y localidades con fechamientos de U-Pb en circones con base en los cuales se propuso la hipótesis original de la megacizalla Mojave-Sonora. Modificado de Anderson y Silver (1979). También se señalan las principales localidades de depósitos cratonales en el norte de Sonora y depósitos eugeosinclinales en Sonora central. El recuadro muestra la distribución de terrenos tectonoestratigráficos en el norte de México y otros rasgos tectónicos.

de México (Pindell y Dewey, 1982; Pilger, 1978; entre otros). Este traslape es inevitable y requiere reposicionar buena parte de México, pero como muestra la Figura 2, reconstrucciones recientes no requieren desplazamiento significativo del norte de México pues el traslape principal ocurre entre Sudamérica y el sur y sureste de México. La hipótesis en su concepción actual fue presentada en un elaborado modelo de la evolución de la región circum- Golfo de México publicada por Anderson y Schmidt (1983). En este modelo, fallas cogenéticas a lo largo de la Faja Volcánica Transmexicana y la Trinchera Mesoamericana acomodaron movimiento de bloques corticales del centro y sur de México en un sentido similar al de la MMS (Figura 3).

Otros lineamientos en el norte de México con una orientación general NW-SE pueden o no estar ligados a la hipótesis de la MMS (Figura 4). Autores como De Cserna $(1971$; 1976) han sugerido la existencia de estructuras regionales, como el lineamiento Torreón-Saltillo, con esa orientación general, basados en la tendencia de pliegues y fallas de la Sierra Madre Oriental y otras observaciones. De esos lineamientos las fallas de La Babia (Charleston, 1981; también llamada lineamiento Boquillas por Padilla y Sánchez, 1986) y San Marcos (McKee et al., 1984, 1990), en Coahuila al norte de la traza hipotética de la MMS, son las mejor documentadas. La falla de La Babia representa el límite entre la cuenca de Sabinas y la plataforma BurroPeyotes, para la cual se ha inferido una componente de corrimiento lateral izquierdo por el posible desplazamiento del arco Tamaulipas con respecto a la plataforma BurroPeyotes (Charleston, 1981; Padilla y Sánchez, 1986). La falla tiene un rumbo $\mathrm{S} 55^{\circ} \mathrm{E}$. La falla de San Marcos está 


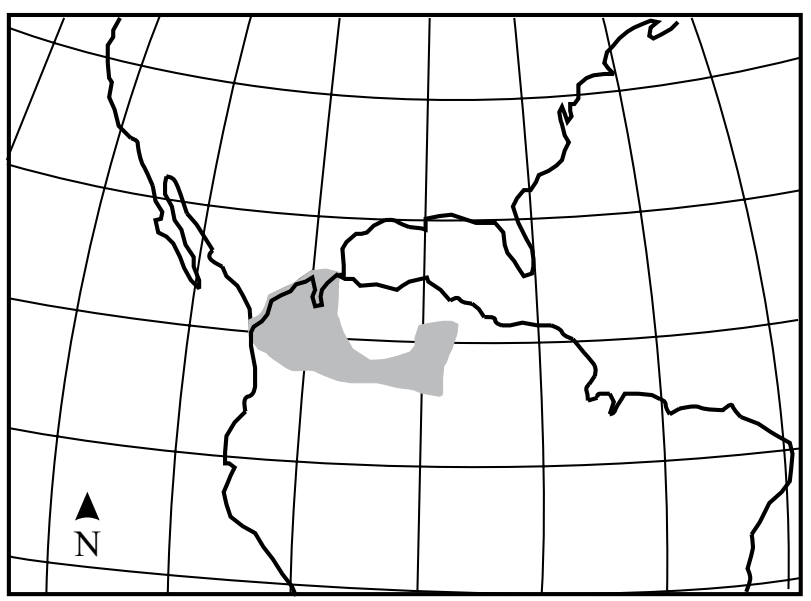

Figura 2. Reconstrucción de las masas continentales de América del Sur y América del Norte en la configuración de Pangea de Lottes y Rowley (1990) mostrando el traslape de América del Sur sobre gran parte del sur de México (gris).

situada entre la cuenca de Sabinas y la paleoisla de Coahuila (el arco Las Delicias). La falla de San Marcos fue claramente activa durante el Jurásico Tardío, principalmente como una falla normal (Chávez-Cabello et al., este volumen). Otra estructura conceptualmente ligada a la MMS es el lineamiento Texas. Este lineamiento se manifiesta como un cinturón de fracturamiento en el oeste y centro de Texas, ejemplificado por la falla de Balcones, que corre de la región SW de Texas hacia la porción central del estado; sobre esta estructura ocurre además vulcanismo terciario.

La continuación oriental de la MMS se infiere a partir de estudios de escasos afloramientos de rocas preOxfordiano en el centro de México (e.g., Jones et al., 1995). La traza se proyecta bajo la cubierta volcánica de la Sierra Madre Occidental y se extiende al sur del bloque de Coahuila, al sur de los afloramientos del arco Las Delicias del Paleozoico superior, y continúa sobre la cuenca de Parras. En esta región, el lineamiento SaltilloTorreón o el lineamiento Torreón-Monterrey (De Cserna, 1976) pueden representar la continuación de la MMS. No obstante, estas estructuras acomodan el cabalgamiento laramídico del frente de las sierras de Parras, Jimulco y la curvatura de Monterrey, sobre la cuenca Parras-La Popa. La cubierta sedimentaria cenozoica no permite definir una posible continuación más oriental, en la planicie costera. El lineamiento de San Tiburcio, con dirección NW-SE en el norte de Zacatecas ha sido interpretado como una falla regional con corrimiento lateral izquierdo (Mitre-Salazar, 1989), quizá también relacionada a la MMS.

Así mismo, la hipotética falla MMS se proyecta del noroeste de Sonora a la región del desierto del este de California y sur de Nevada. Varios autores han señalado que la traza propuesta en su continuación al noroeste en el Desierto Mojave corta patrones y tendencias en la estratigrafía (por ejemplo en isopacas y cambios de facies) aparentemente continuos en rocas del Paleozoico al Triásico (Cameron, 1981; Walker y Wardlaw, 1989). Stone y Stevens (1988) y Walker (1988) proponen, además, que la margen cordillerana de California fue truncada en el Paleozoico tardío, en el contexto que provee la orogenia Sonoma. En esta región, la evidencia de que la margen continental fue truncada incluye patrones de sedimentación en el Misisípico y Pensilvánico y la aparente abrupta terminación de las tendencias estratigráficas del Paleozoico inferior en la región oeste de Nevada (Stevens et al., 1992). Aun si la margen cordillerana fue truncada por corrimientos laterales, la actividad de la falla durante el Jurásico Medio-Tardío, como sugiere el modelo de la MMS, es un elemento de la hipótesis inicial que no ha sido demostrado.

El objeto de este manuscrito es presentar la información recopilada sobre el tema de la megacizalla Mojave-Sonora desde su introducción y evaluar la evidencia que favorece el modelo, o lo contradice. Una conclusión definitiva sobre la validez del modelo, desde el punto de vista de los autores, no está todavía al alcance. También presentamos alternativas al modelo que expliquen las observaciones generales estratigráficas, estructurales, geofísicas y geoquímicas.

\section{Geología general de Sonora}

El basamento precámbrico cristalino en el NW de México fue primero reconocido por Cooper y Arellano (1946) quienes identificaron una fauna del Cámbrico Medio en la secuencia sedimentaria de la región de Caborca sobre un basamento metamórfico. Damon et al. (1962) hicieron

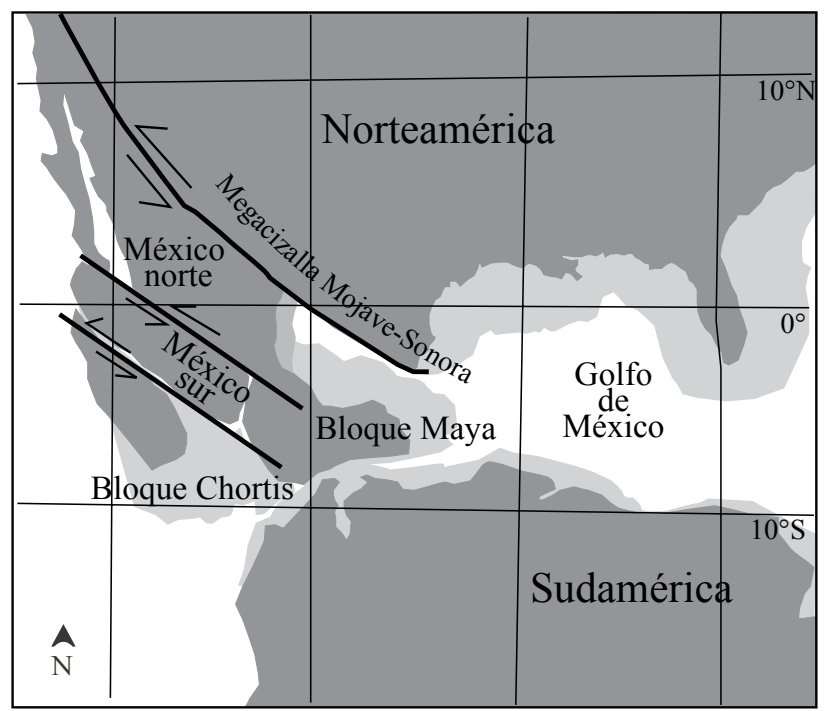

Figura 3. Reconstrución paleogeográfica de la región circum- Golfo de México de acuerdo al modelo de Anderson y Schmidt (1983). En reconstrucciones más recientes, como Lottes y Rowley (1990) la región actual del Golfo se encuentra ocupada por el bloque Yucatán y las masas continentes se encuentran más próximas. Las plataformas continentales se muestran en gris claro si corregir por efectos de atenuación. 


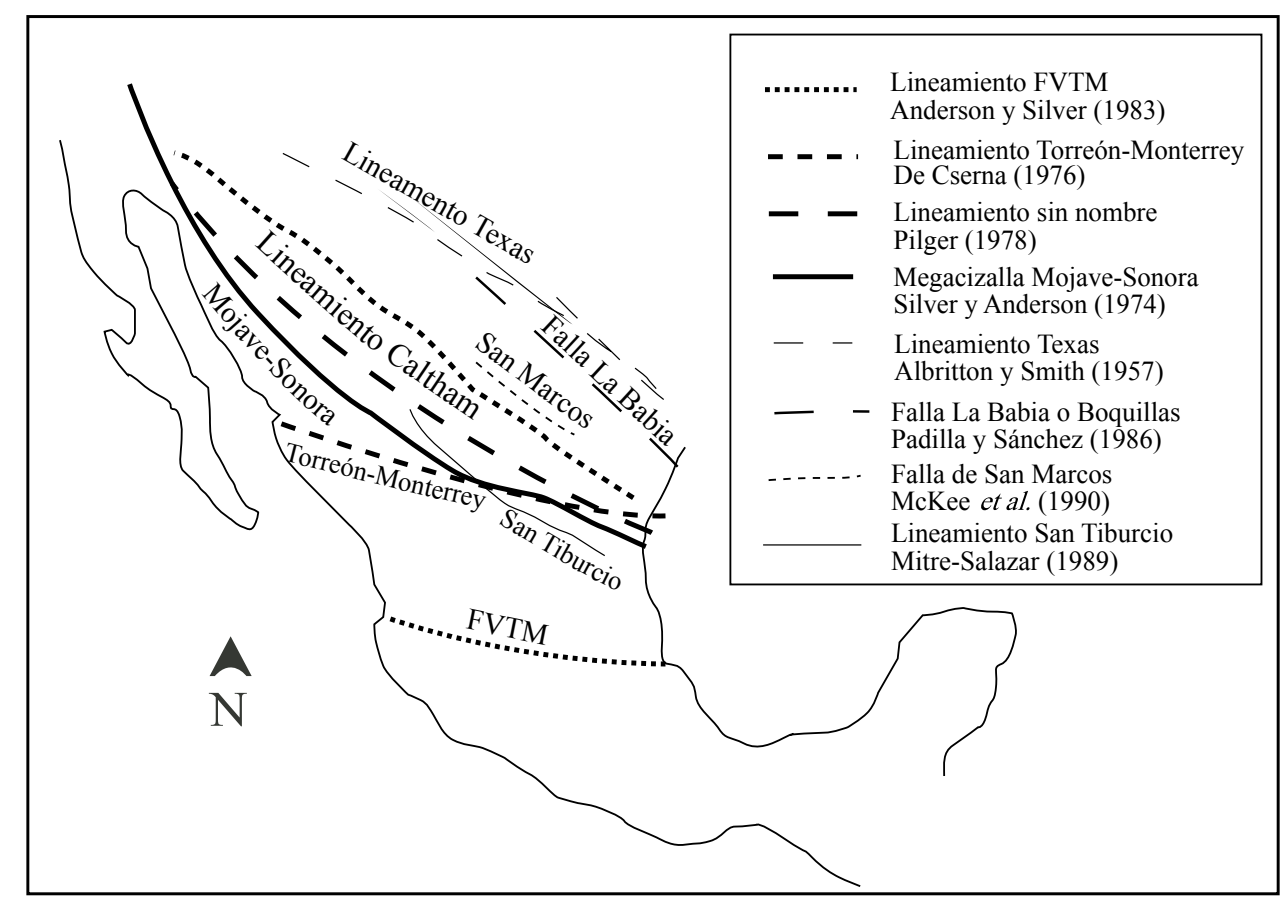

Figura 4. Estructuras o lineamientos regionales propuestos por diferentes autores para el norte de México, que pueden o no estar asociados a la hipótesis de la megacizalla Mojave-Sonora.

los primeros fechamientos radiométricos (K-Ar) en el basamento Paleoproterozoico, identificando también en la región la presencia de magmatismo de edad Grenvilleana (aproximadamente $1.0 \mathrm{Ga}$ ). Más tarde, Anderson y Silver (1977) describieron el basamento como una serie metamórfica del Paleoproterozoico ( $c a .1 .8 \mathrm{Ga}$ ), el Complejo Bámuri; estos autores describieron el Complejo Bámuri como una secuencia volcano-sedimentaria con metamorfismo en facies de anfibolita a esquistos verdes $(c a .1 .65 \mathrm{Ga})$, intrusionada por granitoides con edades $c a$. 1.4 y $1.1 \mathrm{Ga}$.

Los primeros mapas geológicos y una estratigrafía generalizada de la región de NW de Sonora fueron publicados por Merriam (1972) y Merriam y Eells (1979); mientras que la estratigrafía y correlación de la secuencia sedimentaria del Neoproterozoico y Paleozoico fue realizada por Stewart et al. (1984) y Longoria y Pérez (1979). La geología general pre-Jurásico distingue tres provincias: el norte de Sonora, la región de Caborca-Hermosillo y la región sur-centro de Sonora. Estas provincias se han incorporado en la literatura moderna dentro del modelo de terrenos tectonoestratigráficos (Figura 1-recuadro), correspondiendo repectivamente a los terrenos Norteamérica, Caborca (o Seri) y Cortés (Campa y Coney, 1983; Sedlock et al., 1993).

\subsection{Terreno Caborca}

Las unidades más características de la región CaborcaHermosillo pertenecen al Neoproterozoico y Paleozoico. Aquí la geología pre-Mesozoico consiste en carbonatos y rocas siliciclásticas, consideradas parte de la secuencia miogeosinclinal cordillerana expuesta a lo largo del borde oeste de Norteamérica. La secuencia descansa discordante sobre el basamento Proterozoico, tiene un espesor estimado de $3.3 \mathrm{~km}$ y fue depositada en ambientes someros de plataforma en la margen pasiva de Laurencia desarrollada después del rompimiento del supercontinente Rodinia en el Neoproterozoico (Stewart et al., 2002). Solo localmente se encuentran preservadas unidades del Paleozoico medio (Siluro-Devónico); también es aparente un hiatus en el Silúrico (Poole et al., 2000) y existe una aparente discontinuidad en la región de Hermosillo que separa el Pérmico del resto de la secuencia (Stewart et al., 1997). La secuencia miogeosinclinal cordillerana está plegada; los pliegues tienen vergencia hacia el E-NE y localmente cabalga secuencias mesozoicas (De Jong et al., 1988). Esto ha llevado a estos autores a sugerir que la traza de la MMS está regionalmente cubierta por un cinturón de cabalgaduras de edad Cretácico.

Rocas del Paleozoico superior en el terreno Caborca incluyen rocas carbonatadas del Devónico, Misisípico y Pensilvánico (Brunner, 1976; Stewart et al., 1997) de ambientes de plataforma. En la Sierra Santa Teresa, cerca de Hermosillo (Figura 5) la secuencia del Paleozoico superior tiene más de $2000 \mathrm{~m}$ de espesor. Una secuencia siliciclástica de agua profunda de aproximadamente $600 \mathrm{~m}$ de espesor del Pérmico Inferior a medio puede representar depósitos de antepaís de un orógeno situado al sur en la paleogeografía actual o el desarrollo de una cuenca marginal por fallamiento transtensional (Stewart et al., 1997). Sobre la 


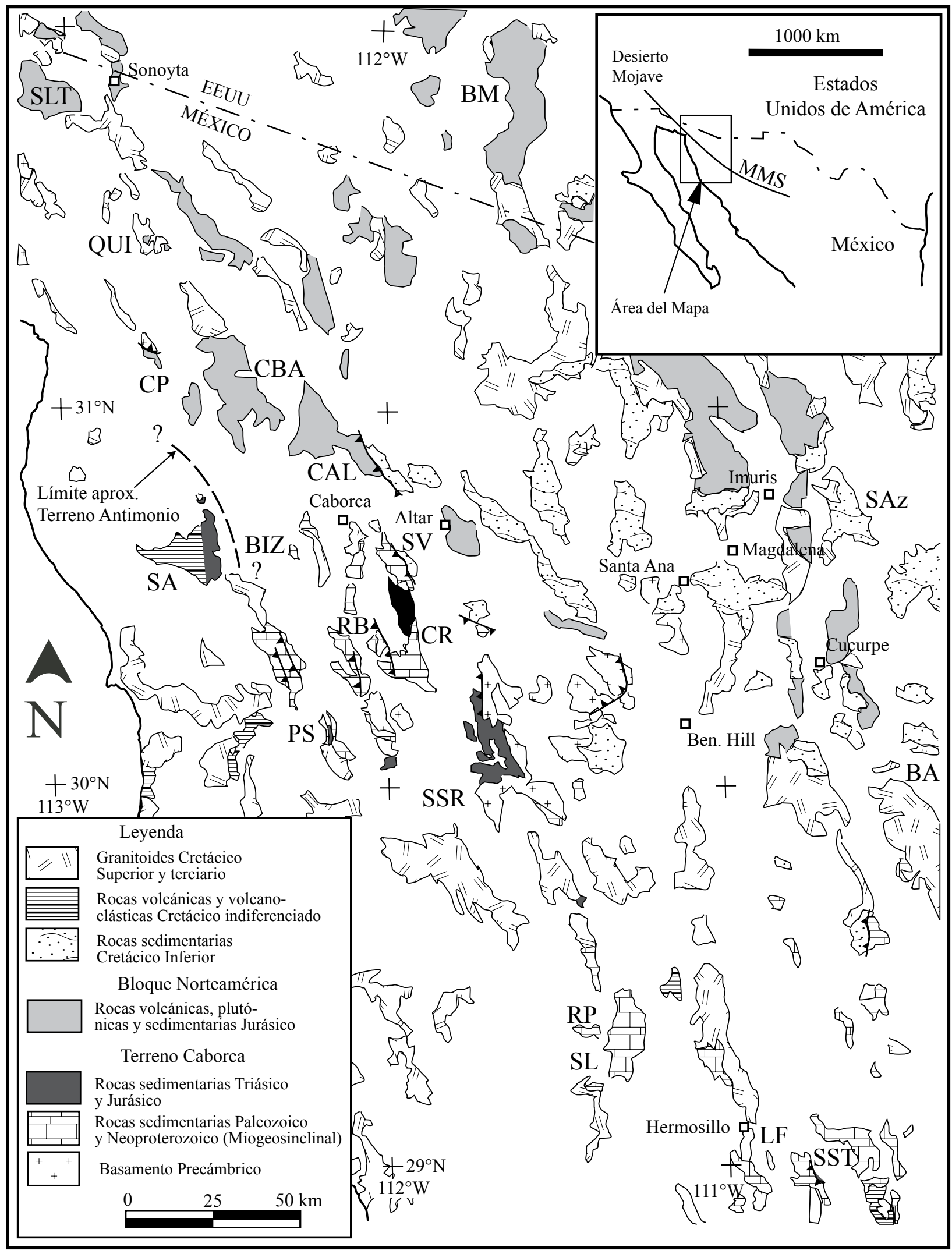

Figura 5. Geología pre-terciario simplificada del NW de México y SW de Arizona, modificado de Molina-Garza y Geissman (1998). Abreviaciones para localidades de interés: $\mathrm{SLT}=$ Sierra Los Tanques; $\mathrm{QUI}=$ Quitovac; $\mathrm{SLG}=$ Sierra La Gloria; $\mathrm{CAL}=\mathrm{Cerro}$ Álamo; $\mathrm{CP}=\mathrm{Cerro} P$ rieto; $\mathrm{SA}=\mathrm{Sierra}$ del Alamo; CR= Cerro El Rajón; SSR= Sierra Santa Rosa; BIZ= Bizani; RB= Rancho Bámuri; SL= Sierra de López; SST= Sierra Santa Teresa; BA= Batolito de Aconchi; PS=Sierra Pozos Serna, LF= Sierra La Flojera, RP= Rancho Placeritos, $S A z=$ Sierra Azul, SV= Sierra la Víbora, CBA= Cerro Basura, SLT= Sierra Los Tanques; BM= Montañas Boboquivari. 
secuencia del Paleozoico descansa discordantemente una sucesión mesozoica de ambientes transicionales y marinos (Formación Santa Rosa y secuencias equivalentes, González-León, 1980). La discordancia entre las secuencias Mesozoico y Paleozoico no está bien expuesta excepto quizás en localidades en el este del Cerro Pozos de Serna (Calmus et al., 1997, Lucas et al., 1999), al sur del cerro El Rajón (Stewart et al., 1984), en Sierra Santa Rosa (Hardy, 1981) y quizá en la región de Rancho Placeritos (Poole et al., 2000, Figura 5).

En su definición original, la Formación Antimonio tiene un espesor de 3 a 4 km (González-León, 1980). La unidad fue subdividida por este autor en un miembro inferior del Tríásico y un miembro superior Jurásico. Del miembro inferior Lucas y Estep (1999) han identificado una fauna de amonitas con un rango de edad del Spathiano (Triásico inferior) al Nórico. En ese trabajo, Lucas y Estep (1999) revisan la estratigrafía y restringen el uso de Formación Antimonio al miembro inferior de González-León (1980) con una edad del Spathiano al Cárnico; éste intervalo es principalmente siliciclástico (limolitas rojas y areniscas finas) con intercalaciones de caliza bioclástica. Además contiene conglomerados con clastos de cuarcita y areniscas con petrofacies que indican una fuente cristalina continental (Stanley y González-León, 1995). El ambiente de depósito es marino profundo y gradúa a un ambiente somero en la parte superior; los conglomerados se interpretan como depósitos de talud. Lucas y Estep (1999) asignan facies marinas someras de la parte alta del miembro inferior sensu González-León (1980) a la Formación Río Asunción, la cual está marcada por intervalos de caliza y arenisca con faunas del Nórico al Jurásico Inferior. Una secuencia jurásica que fue originalmente asignada al miembro superior de la Formación Antimonio es re-asignado por Lucas y Estep (1999) a la Formación Santa Rosa (Hardy, 1981). Esta secuencia contiene abundante fauna del Liásico, posiblemente alcanzando en edad el Pliesbachiano (Stanley y González-León, 1995). La Formación Santa Rosa (sensu Lucas y Estep, 1999) fue derivada de la erosión de un terreno volcano-plutónico y consiste en facies de cuenca dominadas por siliciclásticos. Ambientes marinos y transicionales son característicos de la Formación Río Asunción y ambientes fluviales de alta energía se podrían aplicar a un intervalo muy característico en su base que está dominado por conglomerados con abundantes clastos de cuarzo metamórfico, aunque clastos de cuarcita, pedernal y pórfido granítico también están presentes. La secuencia jurásica de la sierra del Álamo, así como unidades equivalentes en el NW de Sonora, en Pozos de Serna (Calmus et al., 1997; Lucas et al., 1999) y en la Sierra Santa Rosa (Hardy, 1981) están caracterizados por facies turbidíticas que indican ambientes profundos. Otras secuencias posiblemente correlacionables con la secuencia Mesozoica inferior de la región de Caborca afloran en las sierras de López, Santa Teresa y La Flojera (en la región de Hermosillo, Lucas y González-León, 1994; Stewart et al., 1997), y en el cerro
El Rajón al este de Caborca (Figura 5; Longoria y Pérez, 1979) donde la componente volcánica es relativamente importante.

El ambiente tectónico de la Formación Santa Rosa en la sierra del Álamo y la Sierra Santa Rosa es probablemente una cuenca de pre-arco desarrollada entre un arco volcánico continental y un complejo de trinchera (González-León, 1997). La aparente ausencia de depósitos de ambientes tectónicos pre-arco y de trinchera al sur de la traza hipotética de la MMS, fue interpretada por Silver y Anderson (1974) como evidencia de que la margen sur del arco continental Jurásico del norte de Sonora fue truncado por la MMS. Esta interpretación debe ser entonces revisada.

\subsection{Terreno Cortés}

En el centro y este de Sonora, las rocas del Paleozoico consisten de facies eugeosinclinales, de agua profunda, que incluyen rocas silicilásticas, carbonatos y pedernal intercaladas con escasas rocas volcánicas, (Stewart et al., 1990). La secuencia está bien expuesta en el área de Barita de Sonora y la Sierra El Aliso, Cerro Cobachi y Sierra El Encinal (Figura 1). La base de la secuencia no se conoce, pero las rocas más antiguas son del Ordovícico. Las facies de ambientes profundos afloran en un cinturón de aproximadamente $140 \mathrm{~km}$ de largo y unos $50 \mathrm{~km}$ de ancho (Stewart et al., 1990). Este cinturón consiste en al menos dos asociaciones de facies, que son en parte similares y en parte distintas a las facies eugeosinclinales de la Cordillera Norteamericana. En la región de Barita de Sonora, la secuencia tiene un espesor mínimo de $700 \mathrm{~m}$. La secuencia consiste en: (1) lutita con graptolites y calizas profundas del Ordovícico Inferior y Medio; (2) pedernal bandeado, lutita y dolomita del Ordovícico Superior; (3) pedernal, lutita arenisca y barita el Devónico; (4) caliza del Misisípico inferior; (5) conglomerado, pedernal y lutita del Misisípico superior; y (6) pedernal, limolita, barita y arenisca del Pensilvánico (Poole et al., 2000). Facies eugeosinclinales también han sido reconocidas en Isla Tiburón y en Baja California.

El abrupto cambio de facies someras de plataforma a facies de agua profunda en rocas del Pérmico Inferior que sobreyacen la secuencia miogeosinclinal se ha interpretado como evidencia del emplazamiento del "alóctono sonorense", es decir la acreción de las unidades eugeosinclinales del terreno Cortés sobre la margen del terreno Caborca (Stewart et al., 1997). Afloramientos de rocas de facies profundas del Pérmico (Formación Monos) en el NW de Sonora en la sierra del Álamo, son anómalos en el sentido que no existen facies similares en el noroeste de Sonora. El trabajo de Valencia-Moreno et al. (1999) sobre la firma isotópica de granitoides laramídicos sugiere que el terreno Cortés cabalga al margen del terreno Caborca.

La secuencia eugeosinclinal fue cubierta en discordancia por rocas siliciclásticas continentales del Grupo 
Barranca del Triásico, después de su cabalgamiento sobre el miogeosinclinal. El Grupo Barranca comprende una unidad de lechos rojos continentales de edad pre-Cárnico superior, asignada a la Formación Arrayanes, una unidad ciclotémica con capas de carbón e intercalaciones marinas de edad Cárnico superior, asignada a la Formación Santa Clara, y una unidad de potente espesor de conglomerados de la Formación Coyotes (Stewart y Roldán-Quintana, 1991). El Grupo Barranca se depositó en ambientes fluviales, deltaicos y marinos someros, excepto la Formación Coyotes que se formó en abanicos aluviales y cubre en dicordancia erosional a la Formación Santa Clara. La Formación Coyotes es una posible liga estratigráfica entre depósitos post-Triásico sobre Sonora, ya que afloramientos de conglomerado dominado por clastos decimétricos a centimétricos de cuarcitas afloran desde Sonoita, en el extremo NW de Sonora, hasta el límite oriental de los afloramientos del Grupo Barranca en el centro-este de Sonora.

\subsection{Bloque Norteamérica}

En el norte de Sonora, el basamento Paleoproterozoico aflora esporádicamente y consiste principalmente de esquistos y rocas metavolcánicas asociadas, intrusionadas por granitoides del Mesoproterozoico (1.4 y $1.1 \mathrm{Ga})$. La cubierta sedimentaria en el norte de Sonora es de menor espesor que en la región de Caborca y consiste principalmente de facies cratonales y de plataforma que afloran escasamente (Krieger, 1961; Anderson y Silver, 1977) y están representadas por la Cuarcita Bolsa y carbonatos de la Formación Abrigo. La sucesión del Paleozoico superior es similar a la que aflora en el norte de Chihuahua y sur de Arizona.

Sobre la cubierta paleozoica e intrusionando esta secuencia existen rocas volcánicas y plutónicas de Jurásico Medio y Superior que se consideran como una extensión del arco Jurásico continental del sur de Arizona. En la región SW de Arizona y NW de Sonora rocas del basamento y rocas del Paleozoico afloran escasamente, por lo que rocas de esta región se asignan al terreno Pápago (Haxel et al., 1984; Tosdal et al. 1989). La secuencia incluye rocas piroclásticas, volcanoclásticas, fanglomerados, tobas y derrames; en su parte sur contiene también rocas sedimentarias entre las cuáles dominan conglomerados volcánicos y carbonatos. Las rocas volcánicas varían en composición de ácida a intermedia; este arco se construyó claramente sobre un basamento continental. La secuencia volcánica jurásica ha sido cartografiada y descrita en Sonora por Corona (1979), Nourse (1995), Rodríguez-Castañeda (1984; 1994) e Iriondo (2001); y por Haxel et al. (1984) y Tosdal et al. (1989) en Arizona. La secuencia aflora extensamente en las sierras al norte de Caborca y al norte de Santa Ana, aun si comúnmente está afectada por intensa deformación y metamorfismo del Cretácico Superior y terciario medio. De acuerdo con Anderson y Nourse (1998), porciones del arco
Jurásico fueron cortadas por fallas de orientación NW-SE en el Jurásico Tardío, paralelas a la MMS, formando cuencas alargadas y rellenadas por conglomerados sintectónicos y rocas sedimentarias marinas del Cretácico Inferior (Grupo Bisbee y secuencias correlacionables).

\subsection{Estratigrafía y tectónica post-Jurásico}

En el norte de Sonora, pero sobre rocas de los terrenos Norteamérica y Caborca, se encuentra una secuencia continental, transicional y marina somera del Jurásico Superior y Cretácico Inferior que se asigna al Grupo Bisbee y a unidades parcialmente equivalentes (como las formaciones Cerro del Oro, El Represo, Arroyo Sasabe, etc.; González León y Lucas, 1995; Jacques-Ayala et al., 1990; entre otras). El Grupo Bisbee es una unidad de gran distribución en Sonora, Arizona y Nuevo México y se interpreta como una secuencia depositada en ambientes extensionales de tras-arco. Litologías comunes son conglomerado de rocas volcánicas, arenisca y lutita roja, carbonatos y localmente rocas volcánicas. Es notable la baja frecuencia de clastos derivados del basamento cristalino o las secuencias marinas del Neoproterozoico y Paleozoico (Jacques-Ayala, 1995) a pesar de que estudios de paleocorrientes indican fuentes hacia el sur. Sobre la secuencia Cretácico Inferior son comunes los depósitos de rocas volcánicas de composición intermedia (Jacques-Ayala et al., 1990), que además afloran extensamente en el centro y este de Sonora donde se asignan a las formaciones la Palma y Tarahumara (Amaya-Martínez et al., 1993; García y Barragán y Jacques-Ayala, 1993).

Tanto las rocas del Grupo Bisbee como las unidades más antiguas están intrusionadas por rocas plutónicas. Es posible reconocer stocks y cuerpos subvolcánicos que varían de dimensiones pequeñas a medianas en el Cretácico Superior y grandes cuerpos batolíticos en el terciario inferior; inicialmente estas rocas fueron incluidas en el llamado batolito laramídico (Damon et al., 1983) y fueron emplazados entre 90 y $40 \mathrm{Ma}$. La gran mayoría son granitoides de la serie calcialcalina, e incluyen granitos peraluminosos de dos micas. Los batolitos, tipificados por el intrusivo de Aconchi (Figura 5), afloran generalmente en sierras alargadas en la dirección norte-sur producto de la tectónica extensional del terciario.

De Jong et al. (1988) reconocen un evento compresivo del Cretácico medio, que no afecta a cuerpos de granodiorita con edades $c a$. $80 \mathrm{Ma}$ en la Sierra La Víbora al este de Caborca (Figura 5). La deformación de esta edad se asigna a la Orogenia Sevier del oeste de Estados Unidos. Una deformación del Cretácico Tardío a terciario temprano ha sido identificada en el sur de Arizona, en el extremo NW de Sonora y en la región de Altar (Hayama et al., 1984; Damon et al., 1962; Iriondo, 2001); en estas regiones son evidentes el metamorfismo y la deformación dúctil que afecta principalmente a rocas de la secuencia del arco jurásico continental y del Grupo Bisbee. Rocas metamórficas 
resultado de este evento se asignan al Esquisto Altar y podrían representar la extensión SW del Esquisto Orocopia de California (Jacques-Ayala y De Jong, 1996). De hecho, parte del área general entre Altar y Sonoita corresponde a un cinturón metamórfico de bajo grado, del que alguna vez se especuló una única relación con la actividad jurásica de la MMS. Sin embargo, el hecho de que el protolito de esa secuencia metamórfica (Esquisto Altar) es localmente del Cretácico Tardío (García y Barragán et al., 1998) invalida esa interpretación. Este cinturón tiene importancia económica ya que contiene mineralización de oro en zonas de cizalla (Clark, 1998; Iriondo y Atkinson, 2000). En el este de Sonora, en la región de Sahuaripa, Pubellier et al. (1995) reconocen un sistema de cabalgamientos de Cretácico medio. La deformación del Cretácico Tardío es parcialmente contemporánea al depósito de la Formación Tarahumara y unidades correlacionables. En el noreste de Sonora, en la Cuenca de Cabullona, la deformación compresiva afectó a rocas del Cretácico Superior y semeja en estilo a la deformación de basamanto de edad Laramide de las montañas Rocosas (González-León y Lawton, 1995).

Los principales eventos del terciario son: (1) el emplazamiento de rocas volcánicas ácidas de la Sierra Madre Occidental; (2) el desarrollo de complejos de núcleo metamórfico (Nourse, 1990; 1995); y (3) extensión tipo provincia de Cuencas y Sierras - también ligada a la apertura de la Provincia extensional del Golfo de California (Henry y Aranda-Gómez, 2000). Aunque la geología del terciario está fuera del alcance de este trabajo, es necesario considerar los efectos de dicha actividad. Es importante mencionar, por ejemplo, que la fábrica tectónica impuesta en rocas del Precámbrico al Mesozoico por la contracción laramídica y la extensión de tipo de complejo de núcleo metamórfico complica la interpretación de estas secuencias expuestas a lo largo de la traza hipotética de la MMS, al norte y este de Caborca, así como en la región de Opodepe.

\section{Discusión de la evidencia geológica de la megacizalla Mojave-Sonora}

3.1. Yuxtaposición de provincias de basamento precámbrico

Como mencionamos anteriormente, rocas metavolcánicas y metasedimentarias en facies de anfibolita a esquistos verdes y asignadas al Complejo Bámuri están cortadas por intrusivos de composición calcialcalina con edades de cristalización del Paleoproterozoico entre 1.71 y $1.75 \mathrm{Ga}$ (Anderson y Silver, 1981). Las edades de metamorfismo de la secuencia varían alrededor de $1.66 \mathrm{Ga}$; granitos de $1.4 \mathrm{y}$ $1.1 \mathrm{Ga}$ intrusionaron localmente la secuencia metamórfica y no están deformados o metamorfizados (Anderson y Silver, 1981). Este basamento contrasta con rocas expuestas en el norte de Sonora, que tienen edades de cristalización en el rango de 1.6 a $1.7 \mathrm{Ga}$ (Figura 1). Un modelo simplista de la distribución de provincias de basamento en el norte de México que se esperaría de acuerdo con el modelo de la MMS se muestra en la Figura 6.

Las series del basamento metamórfico de Sonora no han sido estudiadas en detalle, pero se interpretan como secuencias de arco volcánico acrecionadas al cratón de Norteamérica por comparación con series mejor estudiadas en Arizona y Nuevo México. La clave de la correlación del basamento del terreno Caborca con la provincia Mojave del sur de California es una serie de observaciones que sugieren que este arco se desarrolló sobre una corteza más antigua, es decir el magmatismo incorporó elementos de una corteza del Arqueano. En el único trabajo detallado del basamento Precámbrico del terreno Caborca, en Quitovac en el extremo NW de Sonora (Figura 5; Iriondo et al., 2004) se reportan edades de cristalización para el basamento al sur de la traza de la MMS, basado en geocronología U-Pb de circones, en el rango entre 1.78 y $1.69 \mathrm{Ga}$. La herencia de corteza más antigua en los granitoides del terreno Caborca no es evidente en circones antiguos, pero quizá sí lo sea con base en los valores de $\varepsilon N d$ observados (entre +0.6 y +2.6 ) y edades modelo de Nd entre 2.07 y $1.88 \mathrm{Ga}$. Las relaciones isotópicas de $\mathrm{Pb}$ en rocas del basamento del terreno Caborca de la región de Quitovac no permiten relacionarlas de manera directa con la provincia Mojave (Iriondo et al., 2004). Estos autores asignan el basamento del terreno Caborca de la región de Quitovac a la transición entre las provincias Mojave y Yavapai.

En marcado contraste con el terreno Caborca, el basamento en el noreste de Sonora se puede correlacionar con la serie Esquisto el Pinal del basamento del sur de Arizona, el cual es asignado a la provincia Mazatzal (Silver, 1965). El basamento Precámbrico del norte de Sonora aflora en

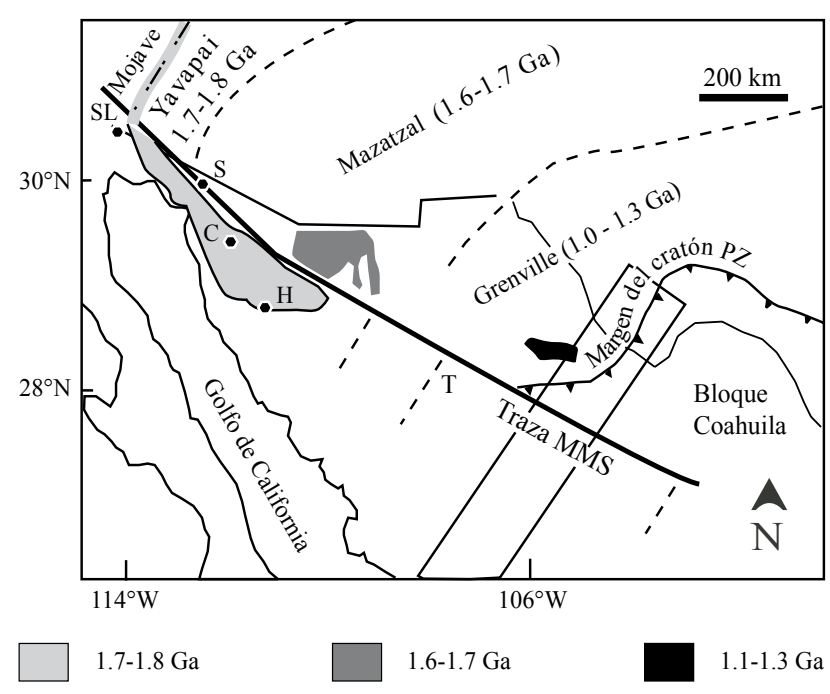

Figura 6. Provincias del basamento Precámbrico en el SW de Norteamérica y localidades de interés en el norte de México. También se muestra el perfil de Cameron et al., 1989 (caja rectangular). Las abreviaciones son: $\mathrm{H}=$ Hermosillo, $\mathrm{C}=$ Caborca, $\mathrm{S}=$ Sonoyta, $\mathrm{SL}=$ San Luis Río Colorado, $\mathrm{T}=$ Caldera de Tomochic. Modificado de McDowell et al. (1999). 
localidades aisladas cerca de Cananea, en Sierra San José, Sierra Los Ajos, Nacozari y Anibacochi. Las litologías dominantes son esquistos de muscovita. Este basamento en México se conoce aún con menos detalle que el Complejo Bámuri, pero se asumen edades de cristalización entre 1.6 y 1.7 Ga similares a las observadas en Arizona (Anderson y Silver, 1981; Anderson y Silver, 1977; Karlstrom y Williams, 1995).

En la región de Quitovac, el basamento del terreno Caborca está yuxtapuesto por fallas dúctiles de edad Cretácico Tardío-terciario temprano a un basamento que Iriondo et al. (2004) describen como terreno "Norteamérica" (Provincia Mazatzal). El rango de edades de cristalización que sugiere la geocronología U-Pb de circones es de 1.71 $\mathrm{Ga}$ a $1.66 \mathrm{Ga}$. El traslape entre las edades de basamento del terreno Norteamérica y el terreno Caborca demuestra que la diferenciación de terrenos en esta sola base, como sugieren Silver y Anderson (1974) en su argumento original que define la MMS, no es posible. Estas rocas del terreno Norteamérica están caracterizadas por valores de $\varepsilon N d$ más empobrecidos $(+3.4 \mathrm{a}+3.9)$ y edades modelo de $\mathrm{Nd}$ de 1.8 a $1.74 \mathrm{Ga}$, también similares a las de la provincia Mazatzal en Arizona.

En resumen, la yuxtaposición de provincias precámbricas distintas en Sonora parece indiscutible, pero la asociación del basamento Caborca a la provincia Mojave no está plenamente demostrada con los datos existentes, ya que podría asociarse también a la zona de transición entre las provincias Mojave y Yavapai, y trabajos más detallados podrán demostrar que el basamento del terreno Caborca es un basamento con componentes de ambas provincias (Figura 7).

\subsection{Desplazamiento de la secuencia miogeosinclinal cordillerana}

La secuencia miogeosinclinal cordillerana aflora extensamente en la región de Caborca. Es formalmente asignada a 14 formaciones (Figura 8) que consisten principalmente de rocas carbonatadas, cuarcitas ultramaduras y rocas siliciclásticas de grano fino. La secuencia sedimentaria del Neoproterozoico no contiene fósiles que permitan determinar su edad con precisión; la secuencia descansa en discordancia erosional sobre el basamento precámbrico cerca del rancho Aibó al SW de Caborca (Granito Aibó; 1.1 Ga; Damon et al., 1962). Aquí la secuencia cubre diques de diabasa que producen edades K-Ar ca. $900 \mathrm{Ma}$ (Damon et al., 1962), edad máxima de la secuencia sedimentaria.

Rocas del Paleozoico inferior incluyen la Cuarcita Proveedora y la Formación Puerto Blanco, con faunas del Cámbrico inferior y Cámbrico medio (Cooper et al., 1952). La Cuarcita Proveedora del NW y centro de Sonora permite correlacionar la secuencia de Caborca con el este de California y Nevada, donde su equivalente por posición estratigráfica es la Cuarcita Zabriskie (Figura 8). De igual manera, una unidad informal dentro de la Formación Johnnie, la oolita Johnnie, del Neoproterozoico se puede identificar en la Formación Clemente del terreno Caborca. Ketner (1986) también identifica la Cuarcita Eureka, del Ordovícico Medio de California y Nevada, en la región de Cerro Cobachi en el terreno Cortés de Sonora central (Figura 1), donde informalmente se conoce como la Cuarcita Peña Blanca. Cabe notar, sin embargo, que la edad de la cuarcita Peña Blanca no está bien determinada. La terminación abrupta de isopacas de la Cuarcita Eureka en la región este de California apoya la hipótesis de que posterior a su depósito, esta unidad fue removida tectónicamente de su posición original en el este de California. Ketner (1986) sugiere que la Cuarcita Eureka se encuentra hoy desplazada en el terreno Caborca. La notable semejanza en tamaño de grano y composición mineral sugiere también que la cuarcita Eureka y la cuarcita Peña Blanca son la misma unidad. No obstante, la correlación entre estas unidades indica un
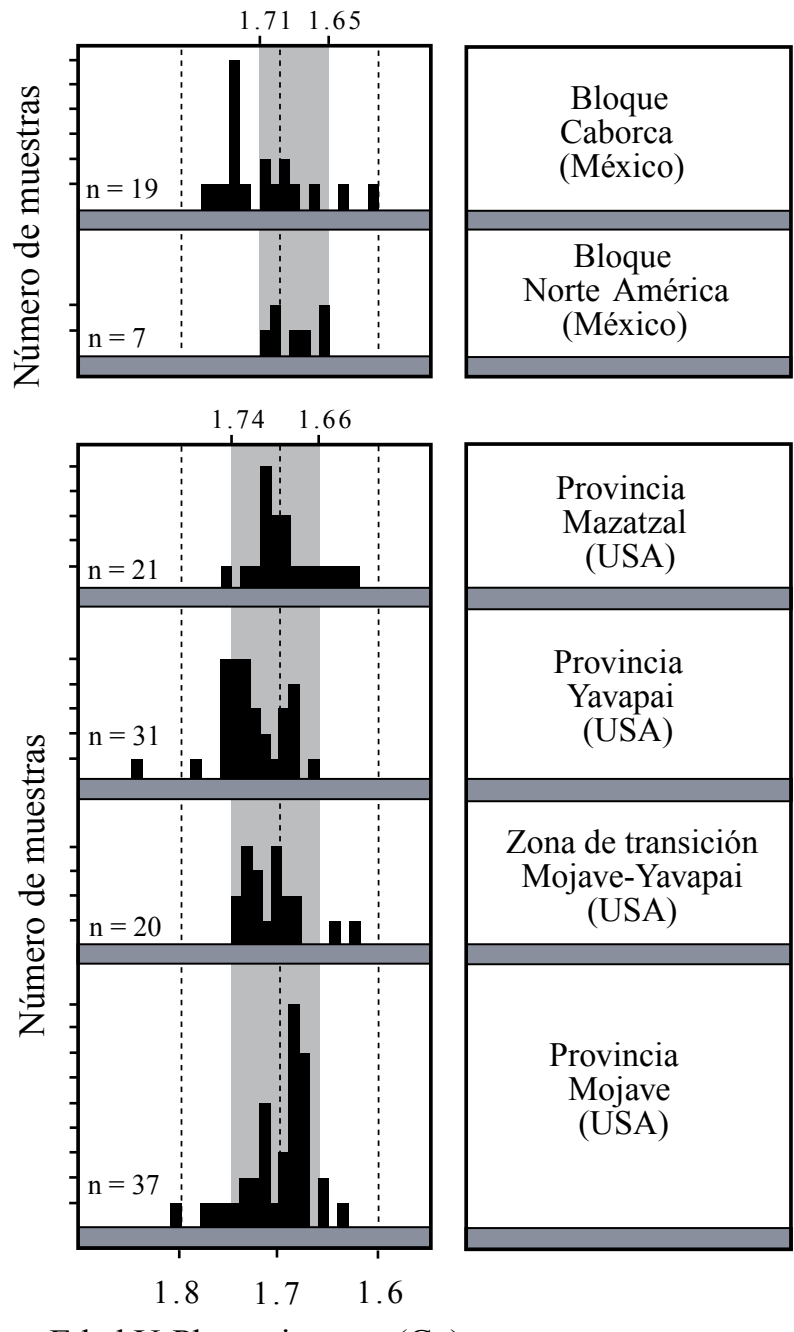

Edad U-Pb en circones (Ga)

Figura 7. Histogramas de edades de U-Pb en las provincias de basamento Precámbrico del SW del cratón de Norteamérica (Modificado de Iriondo et al., 2004). 
Montañas

San Bernardino

\section{Caborca}

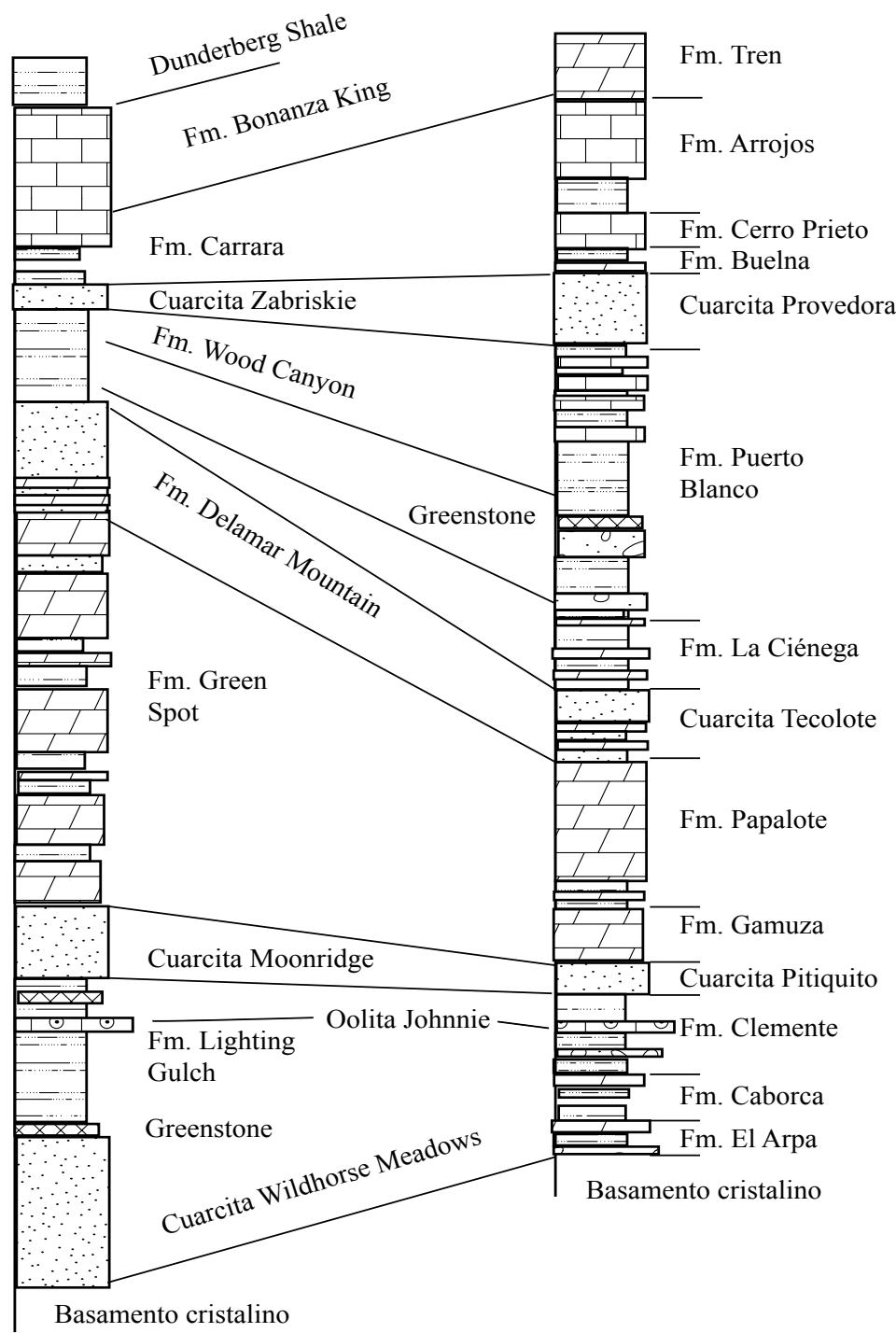

Figura 8. Comparación de las columnas estratigráficas del Neoproterozoico-Paleozoico de Caborca y la región de Death Valley, California. Modificada de Stewart et al. (1984).

desplazamiento del terreno Caborca de aproximadamente $1,200 \mathrm{~km}$. Así pues, no sólo las sucesiones de Caborca y el este de California son correlacionables, sino también unidades individuales comparables existen en ambas sucesiones. Stewart (2003) señala otros elem-entos que ligan la sucesión de Caborca a la Cordillera: la distribución de diamictitas del Neoproterozoico, la distribución de arqueociátidos del Cámbrico Temprano y depósitos del Ordovícico y Devónico de barita estratificada en el alóctono de las Montañas Roberts (Figura 9) y en el alóctono Sonorense. Una prueba esencial para demostrar que la secuencia miogeosinclinal está desplazada, y no una secuencia que envuelve una saliente del cratón, es determinar la tendencia de los patrones estratigráficos (cambios de facies, variaciones de espesor, etc.). En la Cordillera estos tienen una tendencia general norte-noreste (actual), mientras que en
Caborca no existen suficientes datos para establecer esos patrones con precisión. Stewart (2003) sugiere que los datos existentes indican una tendencia norte-sur, apoyando la hipótesis de que la secuencia está desplazada. Sin embargo, la restauración de cerca de $40^{\circ}$ de rotación post-Jurásico Medio determinada por métodos paleomagnéticos (MolinaGarza y Geissman, 1999) haría la tendencia NW-SE, así apoyando la hipótesis de que la secuencia es autóctona y envuelve una saliente del cratón.

El reconocimiento de facies de agua somera, cratonales de poco espesor, en el extremo noreste de Sonora, facies de agua somera miogeosinclinales de gran espesor en la región noroeste y central del estado y facies eugeosinclinales de aguas profundas de espesor variable en la parte sur y central del estado es una observación similar a relaciones observadas a lo largo de la cordillera oeste de Norteamérica 
(Stewart et al., 1984) y sugieren una paleogeografía que no requiere fallamiento importante de la margen SW de Norteamérica. Sin embargo, las facies transicionales entre facies cratonales y facies de plataforma no han sido reconocidas en Sonora. En partes de Sonora que han sido cartografiadas en suficiente detalle, facies eugeosinclinales ocurren estructuralmente bajo la secuencia miogeosinclinal (Ketner y Noll, 1987) o las secuencias están yuxtapuestas por fallas. La yuxtaposición de las secuencias miogeosinclinal y eugeosinclinal en Sonora ocurrió antes del depósito del Grupo Barranca del Triásico superior.

Si bien la estratigrafía de la secuencia miogeosinclinal permite hacer correlaciones directas, Stewart et al. (1990) también hacen notar que no todas las correlaciones son perfectas. La formación Dunderberg Shale, con una amplia distribución en el este de California y el sur de Nevada, con una edad del Cámbrico Superior, no ha sido reconocida en la secuencia del terreno Caborca. Las unidades más jóvenes de la secuencia del Cámbrico en Caborca son las formaciones Abreojos y el Tren, del Cámbrico medio.

Las facies de plataforma del Silúrico en la porción centro-oeste de Sonora (e. g., el área Rancho Placeritos, al oeste de Hermosillo) tienen un significado importante ya que podrían representar la continuación de un cinturón que envuelve el cratón de Norteamérica desde el sur de Texas, a través de Chihuahua y hasta Sonora (Poole et al., 2000). Reconstruir estas facies al NW, de acuerdo con el modelo del MMS, resultaría en una brecha o hueco al oeste de los afloramientos del centro de Chihuahua.

Trabajo reciente en el norte de Sonora y sur de Arizona sugiere que la sucesión cámbrica de Caborca es un terreno autóctono. De acuerdo con Strickland y Middleton (2000) la secuencia cámbrica representa los depósitos en una entrante sobre una margen continua que envuelve el sur del cratón. Los patrones generales de depósito de la Cuarcita Bolsa y la Formación Abrigo, en el norte de Sonora, sugieren que esta entrante se abría hacia el SW durante el Cámbrico medio. Los depósitos de la región de Caborca en esta paleogeografía representan una continuación con facies más profundas (Strickland y Middleton, 2000). Cabe además mencionar que las poblaciones de circones detríticos en la Cuarcita Bolsa y la Cuarcita Proveedora son indistinguibles (Kurtz et al., 1998). En especial, estas unidades comparten la predominancia de circones $c a$. $1.1 \mathrm{Ga}(\mathrm{n}=14$ de 21 circones analizados en las Cuarcita Bolsa, además de tres granos $c a .1 .2 \mathrm{Ga}$ ); esto distingue la Cuarcita Provedora y la Cuarcita Bolsa de cuarcitas en el este de California y sugiere que el terreno Caborca es autóctono con respecto a Norteamérica.

Una secuencia que es aparentemente difícil de incorporar en los modelos que desplazan la secuencia miogeosinclinal, aflora en el Ejido Aquiles Cerdán, cerca de San Luis Río Colorado (Figura 6). Esta secuencia representa esencialmente las facies cratonales de la plataforma del Río Colorado, incluyendo el Grupo Supai, la Arenisca Coconino y la Caliza Kaibab (Leveille y Frost, 1984). La secuencia presenta metamorfismo en facies de esquistos verdes, aunque la edad del metamorfismo no se conoce en detalle. Si esta secuencia es autóctona, como lo sugiere su semejanza con las rocas del centro de Arizona, implica que una posible traza de la MMS debe pasar al sur de esta localidad (Stewart et al., 1990).

\subsection{Proveniencia de circones en cuarcitas}

Una contribución reciente sobre la relación que guarda la secuencia miogeosinclinal de Caborca con el resto de la cordillera, está basada en la proveniencia de circones detríticos en las unidades de cuarcita contenidas en la columna estratigráfica (Gehrels y Stewart, 1998). Aunque las condiciones impuestas por la geología de la región y de los propios datos obtenidos por Gehrels y Stewart (1998) no permiten derivar conclusiones definitivas, algunas observaciones son importantes de mencionar. En el caso de la Cuarcita Proveedora del Cámbrico, por ejemplo, los circones son derivados principalmente de rocas cristalinas de $c a$. $1.1 \mathrm{Ga}$, de $1.40-1.45 \mathrm{Ga}$, y de 1.6 a $1.8 \mathrm{Ga}$, de mayor a menor abundancia. La abundancia de circones $c a$. $1.1 \mathrm{Ga}$ es notable ( $\mathrm{n}=20$ de 35 circones analizados, además de dos granos de $\sim 1.24 \mathrm{Ga}$; Gehrels y Stewart, 1998), ya que no existen fuentes importantes de circones en este rango de edad en el este de California y sur de Nevada. Gehrels y Stewart (1998) señalan que la proximidad de rocas de esta edad en Caborca (e.g. , Granito Aibó) puede indicar fuentes locales, más que una aportación importante de una fuente en la provincia Grenville. Sin embargo, los circones $c a$. 1.25 Ga en esta unidad y los circones en la Cuarcita Bolsa son probablemente derivados de la Provincia Grenville. Rocas de la provincia Grenville están más cercanas en la paleogeografía actual del terreno Caborca, e incluyen posibles fuentes en el sur de Texas y en Chihuahua.

Circones en sedimentos de edad Ordovícico Medio, colectados en la Sierra López, en rocas de la secuencia miogeosinclinal al oeste de Hermosillo (Figura 5) provienen de fuentes distantes. Estos circones muestran edades entre 1.77 y $2.07 \mathrm{Ga}$ (9 muestras) y cinco más dan edades entre 2.47 y 2.90 Ga (Gehrels y Stewart, 1998). Para una cuarcita del Devónico Superior en la sección miogeosinclinal de Agua Verde (al norte de Mazatán, Figura 1) los grupos de edades principales son $\sim 1.43$ Ga (10 granos) y 1.62-1.78 (14 granos). Dos circones adicionales dan edades de 2.07 y $2.47 \mathrm{Ga}$. Estos resultados tampoco permiten hacer distinciones simples entre una paleogeografía del bloque Caborca en el sur Nevada y una paleogeografía cercana a su posición actual.

\subsection{Secuencia eugeosinclinal}

Una inconsistencia notable en el modelo de la MMS que mencionan Poole y Madrid (1988) y que posteriormente 


\section{California}

Montañas Inyo

(Stevens y Stone, 1988)
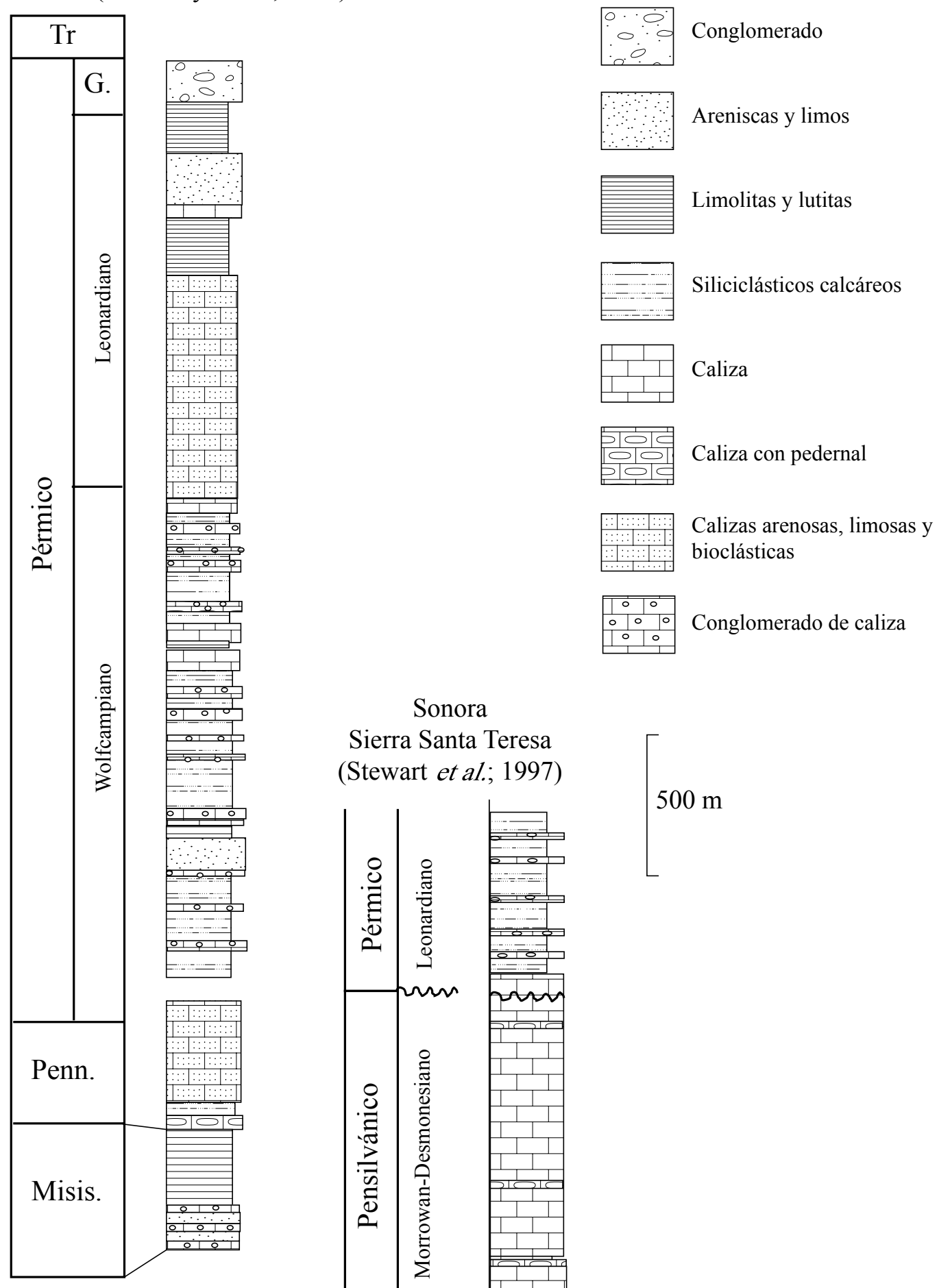

Sonora

Sierra Santa Teresa

(Stewart et al.; 1997)

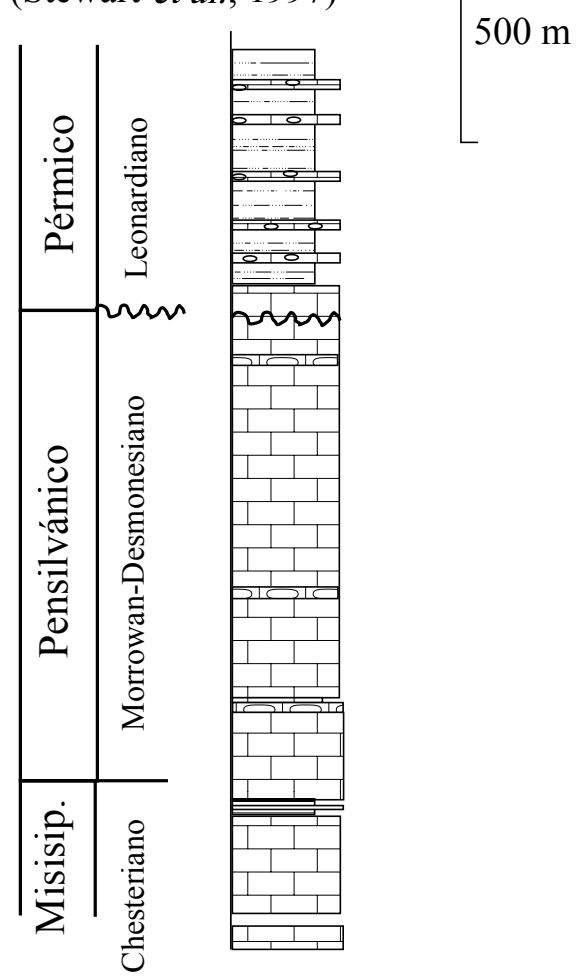

Figura 9. Comparación de las columnas estratigráficas del Paleozoico Superior de la parte sur de las Montañas Inyo, en California (Stone y Stevens, 1988), y de la Sierra de Santa Teresa en Sonora (Stewart et al., 1997). 
desarrollan Stewart et al. (1990) involucra la estratigrafía y tiempo de deformación en la secuencia eugeosinclinal de Sonora central (terreno Cortés, Figura 10). Esta secuencia alóctona comparte muchos rasgos con las secuencias eugeosinclinales de la Cordillera de Norteamérica, incluyendo datos de proveniencia de circones, con una gran abundancia de circones con edades $>2.4 \mathrm{Ga}$ y las asociaciones generales de facies. Con base en el conocimiento actual de las secuencias eugeosinclinales de Sonora y el oeste de Estados Unidos no es posible hacer argumentos que apoyen o invaliden la hipótesis de la MMS pues la edad del cabalgamiento del alóctono de las Montañas Roberts, en Nevada, no está bien definida y la misma orogenia Antler puede no haber ocurrido a un mismo tiempo a lo largo de la margen cordillerana. Pero a diferencia de las secuencias eugeosinclinales de Nevada, que fueron yuxtapuestas durante el Paleozoico medio, las secuencias eugeosinclinal y miogeosinclinal de Sonora central fueron puestas en contacto en el Pérmico (Stewart et al., 1990; Stewart et al., 1997). Poole y Madrid (1988) señalan también que existe una relación entre las secuencias del alóctono Sonorense y el orógeno Ouachita en el oeste de Texas. Esta idea se apoya en la tendencia general SW de facies en Texas y la supuesta continuación con orientación este-oeste en Sonora.

En un artículo reciente, Poole et al. (manuscrito en revisión) desarrollan la idea de que el cinturón OuachitaMarathon se extiende al oeste desde su aparente terminación en la región del Big Bend en Texas, hacia Sonora central. Estos autores interpretan facies y estructuras a lo largo de la margen sur de Laurencia como resultado de una colisión oblicua y diacrónica, en la que las facies de antefosa y los depocentros de cuencas de antepaís se hacen progresivamente más jóvenes hacia el oeste. De acuerdo con el modelo de colisión de Poole et al. (op. cit.) la deformación a lo largo de la margen inició en el Misisípico, y culmina en el Pensilvánico tardío en el segmento Ouachita, en el Pérmico temprano en el segmento Marathon y en el Pérmico tardío en Sonora. Esta diferencia de edades se interpreta como resultado de la rotación antihoraria progresiva de Gondwana durante la colisión. A su vez, la participación del alóctono Sonorense en la orogenia Ouachita requiere una paleogeografía cercana a la actual durante el Paleozoico tardío.

\subsection{Comparación de las secuencias marinas del}

Paleozoico superior del centro-este de California y el terreno Caborca

En el Paleozoico Superior se desarrollaron importantes plataformas calcáreas en la margen suroeste de Norteamérica. En el noreste de Sonora, esta secuencia está representada por las formaciones Escabrosa, Horquilla, El Tigre, Earp y Epitaph del Carbonífero al Pérmico, y que son unidades bien reconocidas en el norte de Chihuahua, en Arizona y en Nuevo México. En el terreno Caborca, la secuencia está representada por una sucesión de 7 unidades informales expuestas en la sierra de Santa Teresa, cerca de Hermosillo (Stewart et al., 1997). La sucesión consiste en aproximadamente 1,500 $\mathrm{m}$ de facies someras de caliza de plataforma (lodolitas calcáreas, y en menor proporción wackestones y packstones) del Misisípico Tardío al Pensilvánico Medio, un hiatus del Pensilvánico Tardío y Wolfcampiano, $100 \mathrm{~m}$ de packstone de fusulínidos y fragmentos de briozoarios del leonardiano y 600 $\mathrm{m}$ de limolita calcárea, arenisca fina y calcarenita del leonardiano a Guadalupiano. Esta sucesión contrasta con el Paleozoico Superior de las Montañas Inyo (Stevens y Stone, 1988), que está caracterizado, por ejemplo, por lutita del Misisípico, arenisca calcárea y limolita bioclástica calcárea del Pensilvánico, una sección expandida $(2,000$ m) del Wolfcampiano de limolita calcárea, calcarenita, conglomerado de caliza y caliza bioclástica del leonardiano a su vez cubiertas por rocas siliciclásticas (Figura 9).

3.6. Correlación de la secuencia marina triásica del NW de Sonora con la provincia marina del Mesozoico de Nevada

Stanley y González-León (1995) han sugerido que las formaciones Antimonio y Río Asunción, del Triásico Inferior-Jurásico Medio (González-León, 1980; Lucas y Estep, 1999), expuestas en la sierra del Álamo Muerto, al oeste de Caborca (Figuras 6 y 10) se pueden correlacionar con la secuencia de la provincia marina del TriásicoJurásico del centro de Nevada (formaciones Luning y Gabbs; Oldow, 1984; Oldow et al., 1993).

En la región de la sierra del Álamo, la Formación Antimonio sobreyace la Formación Monos, que consiste en calizas con fusulínidos gigantes característicos de terrenos alóctonos de la Cordillera, como el terreno Klamath del norte de California. González-León y Stanley (1993) propusieron incluir rocas de la Formación Antimonio y la Formación Monos en el terreno Antimonio, el cual se ha interpretado como alóctono con respecto a la secuencia miogeosinclinal de Caborca (González-León, 1995; Molina-Garza y Geissman, 1996). La aloctonía no se puede demostrar claramente por la presencia de una sutura, pero Lucas y Estep (1999) muestran que las secuencias Río Asunción y Santa Rosa cabalgan la Formación Antimonio. Con base en la correlación de las secuencias triásicas marinas González-León y Stanley (1993) sugieren que el terreno Antimonio es un fragmento de la cuenca marina mesozoica de Nevada desplazado 1,000 km hasta alcanzar su posición actual.

La secuencia basal siliciclástica gruesa de la Formación Río Asunción (conglomerados de cuarcita y cuarzo metamórfico) se inserta entre dos niveles con fauna de amonitas del Hettangiano y del Sinemuriano. Esta misma unidad de conglomerado se ha reconocido en Pozos de Serna, en Sierra Santa Rosa, en Sierra Santa Teresa, (Figura 5) y 


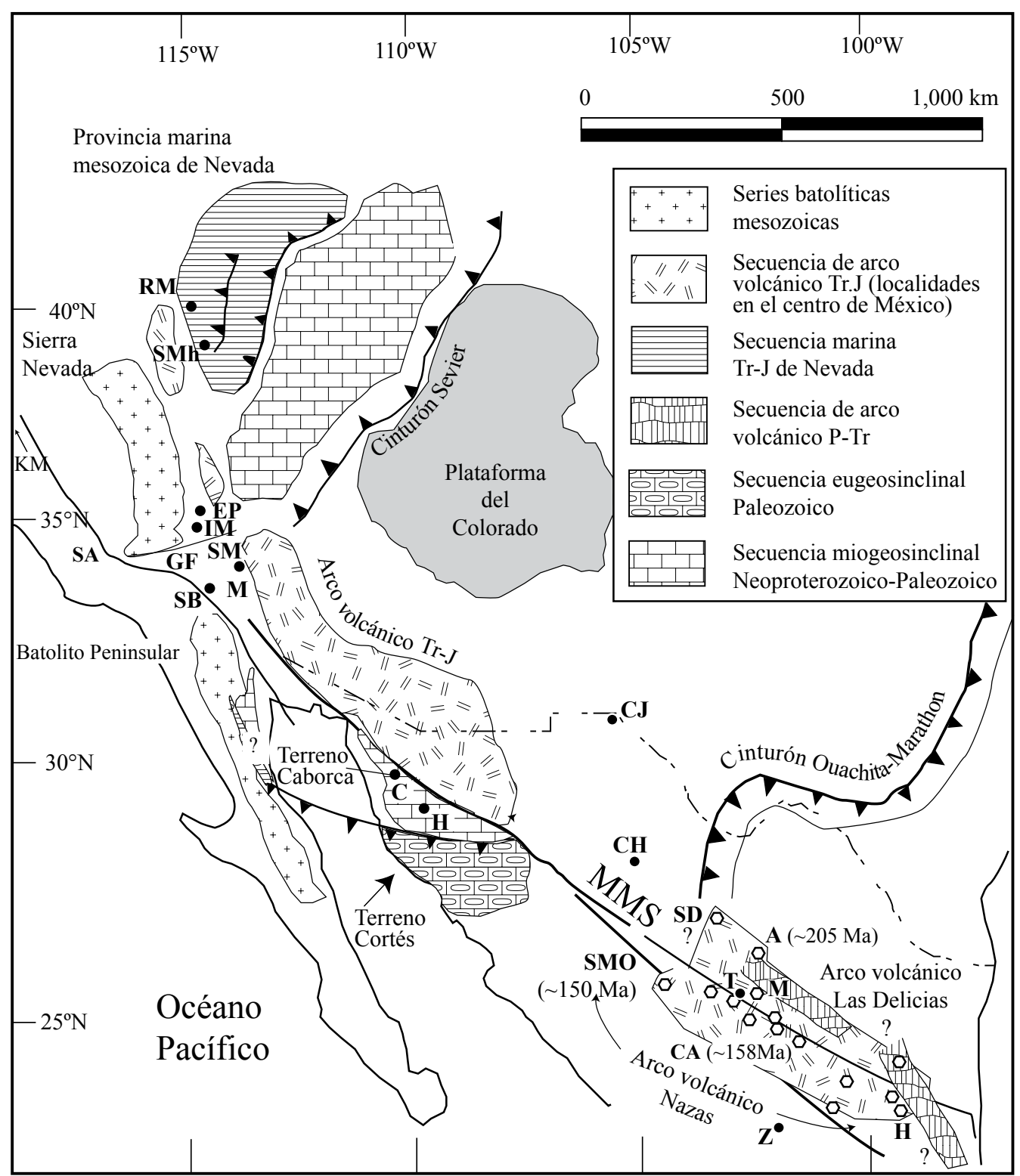

Figura 10. Mapa de elementos tectónicos en el SW de Estados Unidos y norte de México. También se marcan localidades del arco magmático TriásicoJurásico del centro-norte de México (hexágonos abiertos) y localidades de interés en el área del Desierto Mojave (M). Abreviaciones: Localidades en el desierto Mojave: $\mathrm{SA}=$ Falla San Andrés; $\mathrm{SB}=$ Montañas San Bernardino; EP=Montañas El Paso; SM= Montañas Soda; GF= Falla Garlock; IM= Montañas Inyo. Localidades en México: $\mathrm{C}=\mathrm{Caborca}$; $\mathrm{H}=$ Hermosillo; $\mathrm{CH}=$ Chihuahua; $\mathrm{SMO}=\mathrm{Santa}$ María del Oro, $\mathrm{CJ}=\mathrm{Ciudad} \mathrm{Juá} r e z ; \mathrm{SD}=\mathrm{Sierra}$ del Diablo; A= Acatita, Sierra Las Delicias; T= Torreón; CA= Caopas-Pico de Tierra; Z=Zacatecas; H= Valle de Huizachal; M= Pozo Mayrán I; MMS= Megacizalla Mojave-Sonora. Localidades en Nevada incluyen las Montañas Roberts (RM) y las Montañas Shoshone (SMh).

es posiblemente equivalente a la Formación Coyotes del Grupo Barranca que descansa sobre las secuencias mioclinal y eugeosinclinal del centro de Sonora. Estos afloramientos ocurren a lo largo de más de $300 \mathrm{~km}$, además es posible que se extiendan hasta la región de Quitovac en el extremo noroeste de Sonora. Eso sugiere que la aloctonía de un supuesto terreno Antimonio solo sería válida para un tiempo anterior al Jurásico Medio. Esto es porque los conglomerados liásicos de cuarcita yacen sobre secuencias autóctonas con respecto al terreno Caborca en varias localidades (e. g., Calmus et al., 1997).
La correlación entre la secuencia Luning en Nevada y la secuencia de la sierra del Álamo en Sonora está basada, sin embargo, en una fauna arrecifal subtropical de aguas someras del Nórico que carece de provincialismo diagnóstico. Esta fauna está presente en la cima del miembro inferior y contiene taxa de corales, esponjas, bivalvos y cefalópodos con afinidades que permiten asociarla igualmente a faunas del Nórico en la provincia marina del Mesozoico del centrooeste de Nevada, el norte de Perú o la región occidental de Tethys; aun si el mayor número de taxa que comparte la Secuencia de la sierra del Álamo es con la provincia 
marina del Mesozoico de Nevada. La secuencia de la sierra del Álamo también contiene taxa comunes a faunas del Nórico en los terrenos Klamath Oriental y Stikinia. Stanley y González-León (1995) sugieren que espesores y litofacies en la secuencia de la sierra del Álamo se comparan favorablemente con la secuencia en Nevada. Por ejemplo, tanto en Sonora como en Nevada las secuencias contienen intervalos distintivos de calizas en el Nórico. La sucesión de Nevada contiene, sin embargo, una sección expandida del Nórico Medio e Inferior, con importantes espesores de carbonatos en comparación con la secuencia de la sierra del Álamo en donde la misma sección es de menor espesor y está representada principalmente por siliciclásticos.

Revisiones recientes de la zonación de amonoideos en la secuencia de la sierra del Álamo (Gómez-Luna y Martínez-Cortés, 1997; Lucas y Estep, 1999) no apoyan la correlación de Stanley y González-León (1995). Oldow et al. (1993) señalan que las rocas más antiguas en la asociación Lunning son del Triásico Medio (Ladiniano), mientras que Lucas y Estep (1999) reconocen amonitas del Smithiano y Spathiano (Triásico Inferior) en la parte basal de la Formación Antimonio. La fauna de amonoideos de la secuencia de la sierra del Álamo incluye además componentes de la biozona Dilleri (del Cárnico), las biozonas Suessi, Columbianus, Cordilleranus (del Nórico Superior) y la zona Crickmayi del Triásico más tardío (Rético). De acuerdo con Stanley y González-León (1995) esta fauna asemeja la reportada para la parte media de la Formación Gabbs en el centro-oeste de Nevada. Cabe notar que la secuencia mesozoica marina de Nevada contiene una unidad correlacionable con el nivel siliciclástico grueso de la base de la Formación Río Asunción. Sin embargo, litológicamente la Formación Dunlap y la secuencia de la sierra del Álamo no guardan gran semejanza; existe una mayor abundancia de carbonatos de facies someras en la secuencia Liásica de Nevada mientras que estas facies son escasas en el NW de Sonora.

En su correlación de las secuencias de la sierra del Álamo y Nevada, Stanley y González-León (1995) señalan que la fauna de amonoideos característicos de la Zona Crickmayi asemeja una previamente reportada de la Formación Gabbs; al referirse a amonoideos de la Zona Dilleri señalan su afinidad con la fauna de la Caliza Hosselkus de California. Amonoideos de la Zona Dilleri, del Cárnico tardío, ocurren en la sierra del Álamo en facies de estratos delgados de micrita, caliza bioclástica y arenisca de grano fino, interpretadas como facies marinas profundas (González-León et al., 1996). Sobre este intervalo afloran arenisca, limolita y en menor abundancia caliza, culminando con un intervalo de carbonatos impuros (biostromas), interestratificados con lutita. Cerca de la base de este paquete existe una fauna del Nórico Medio y Superior, indicativa de la Zona Columbianus, y en su parte superior existen amonoideos del Nórico Superior (Zonas Columbianus o Cordilleranus, del Nórico Superior inferior). Sobre este paquete se encuentran géneros representativos de la Zona
Amoenum, sobreyacidos por facies de caliza bioclástica, caliza impura y limolita con una fauna del Nórico Superior (Zona Crickmayi) y por encima de este paquete se colectaron amonoideos del Hettangiano Tardío.

Rocas de la Asociación Luning se definieron originalmente en la parte central de las Montañas Pilot, en Nevada, como una secuencia de dolomita oscura, caliza, argilita y lutita, interestratificada con rocas clásticas gruesas. En las Montañas Shoshone se reconocieron tres asociaciones de amonoideos: la fauna "Carnites", del Cárnico; sobreyaciendo concordantemente, existe una fauna característica de la Zona Tropites (Subzona Tropites welleri), del Cárnico Tardío y por último la fauna de Guembelites, del Cárnico Tardío-Nórico temprano (Muller et al., 1936). La zona Guembelites fue referida por Silberling y Tozer (1968) a la Zona Kerri. Por su parte, la Formación Gabbs se definió como lutita y limolita interestratificadas con caliza negra sobreyacida por caliza bioclástica arenosa-arcillosa. La fauna de los estratos inferiores es del Nórico tardío, asignada por Silberling y Tozer (1968) a la Zona Suessi, pero a su vez Tozer (1980) indica que la fauna de esta zona ocurre en todo el Nórico tardío y asignó las capas basales de la Formación Gabbs a la Zona Amoenum. Las faunas de los miembros medio y superior fueron correlacionadas con la Zona Crickmayi (Tozer, 1980).

En la zonación estándar la Zona Dilleri se encuentra debajo de la Zona Welleri. En esta relación no existe una correspondencia entre las sucesiones en Nevada y la de la sierra del Álamo. Además, la secuencia en Nevada, en la Montañas Shoshone, es más completa que en Sonora, incluyendo en orden ascendente la zona Welleri, Macrolobatus, Kerri y Magnus (Gómez-Luna y Martínez-Cortés, 1997). Señalan también estos autores que los biostromas de Nevada (Montañas Pilot) que contienen la misma fauna de esponjas y corales de Sonora, ocurren entre las zonas Kerri y Magnus, mientras que en Sonora se restringen al intervalo (más joven) entre las zonas Columbianus y Cordilleranus. Esta últimas, no tienen representación equivalente en Nevada. Así, en base a la zonación de cefalópodos, GómezLuna y Martínez-Cortés (1997) no encuentran soporte para la correlación de Stanley y González-León (1995).

\subsection{Deformación dúctil con orientación NW-SE que} yuxtapone rocas volcánicas de edad Jurásico con un intrusivo triásico cerca de Sonoita, Sonora

Campbell y Anderson $(1998,2003)$ reportan la existencia de una zona de deformación dúctil en la Sierra Los Tanques, cerca de Sonoita en el norte de Sonora, que interpretan como la traza de la MMS (Figura 5). En esta región una ultramilonita bandeada y milonita de grano grueso desarrollada en granitos de biotita y muscovita, con foliación general vertical NW-SE y un espesor de 1 a $3 \mathrm{~km}$, pone en contacto un granito de edad Triásico (U$\mathrm{Pb}$ en circones) con un pórfido del Jurásico. La zona de 
deformación dúctil tiene una lineación subhorizontal que sugiere desplazamiento lateral, pero observaciones de los autores sugieren que los indicadores cinemáticos no son concluyentes a escala de afloramiento.

También, Caudillo-Sosa et al. (1996) asocian un evento de transpresión que afectó rocas del basamento Proterozoico y rocas del arco volcánico jurásico, en la zona de Quitovac al SW de Sonoita, a la evolución de la MMS. Estos autores argumentan que granitoides Cretácicos no están afectados por la zona de deformación transpresiva. Iriondo (2001) sugiere que estos intrusivos, fechados por U-Pb en circones en aproximadamente $75 \mathrm{Ma}$, son afectados por deformación dúctil en esta zona de Quitovac. Además, aproximadamente $100 \mathrm{~km}$ al norte de Quitovac en las Montañas Comobabi y Baboquivari de Arizona, una deformación con estilo similar asociada a un metamorfismo regional, acompañados de plutonismo, afectan rocas del Jurásico durante el Cretácico tardío y terciario temprano (Haxel et al., 1984). En el Desierto de Altar, $\sim 50 \mathrm{~km}$ al sur de Quitovac, rocas del Proterozoico cabalgan sobre rocas del arco Jurásico en la región norte de la costa del Mar de Cortés cerca de Puerto Peñasco (Calmus y Sosson, 1995).

Campbell y Anderson (1998) reportan que las milonitas de la región de Sonoita registran pliegues recumbentes y verticales. Localmente la lineación es semivertical, con indicadores que sugieren cabalgamientos al NE y SW. Estas estructuras compresionales se atribuyen a transpresión durante el Jurásico, con el desarrollo de una estructura en flor positiva. El problema principal de estas observaciones es determinar la edad de la deformación. En la región se ha identificado deformación dúctil que además del basamento Precámbrico y la cubierta volcánica del arco Jurásico del sur de Arizona y norte de Sonora, afecta granitoides del Cretácico (Iriondo, 2001; Haxel et al., 1984). Más crítico aún para la propuesta de la milonita de Sonoita como parte del sistema MMS, un estudio estructural en la región de Quitovac, unos $20 \mathrm{~km}$ al sureste de la localidad de Sonoita, demuestra que las zonas de deformación dúctil registran principalmente un evento compresional Cretácico Tardíoterciario temprano y fueron basculadas en el terciario medio (Iriondo, 2001). La zona de cizalla expuesta cerca de Sonoita en la Sierra de los Tanques está alineada con una zona de deformación dúctil que corta un granitoide del Cretácico en la Sierra La Toñita (Iriondo, 2001), lo cual sugiere que se trata de una zona de deformación de edad Laramídica. Quizá existan reactivaciones de estructuras anteriores, pero lo que se puede asegurar es que estas deformaciones no son únicamente asociadas a la MSM como se ha planteado durante años.

\subsection{Deformación dúctil en la región de Opodepe y otra} evidencia estructural

En la región de Opodepe, al NE de Hermosillo (Figura 5), deformación dúctil y frágil ha sido también asociada a la MMS (Rodríguez-Castañeda, 1996). Las observaciones consisten en una foliación de orientación NE-SW y buzamientos $>60^{\circ}$, con indicadores de desplazamiento diestro, que afecta a rocas del Proterozoico y que se interpretan como una estructura dúctil asociada a una falla antitética a la MMS. La edad jurásica de la falla, se interpreta con base en "consideraciones tectónicas regionales" (RodríguezCastañeda, 1996). La deformación se interpreta como anterior al emplazamiento de un granito alcalino de $\sim 36 \mathrm{Ma}$, aunque el plutón también registra una fábrica NE-SW. Esta zona de milonitización podría estar asociada a una zona de deformación del terciario medio de tipo de complejo de núcleo metamórfico (metamorphic core-complex), por lo que separar una fábrica proterozoica, de una fábrica jurásica y a su vez de una fábrica terciara es difícil, si no imposible. Evidencia de un complejo de núcleo metamórfico en la región de Opodepe no es, sin embargo, del todo clara (Calmus et al., 1997) y podría tratarse de una milonita de edad Precámbrico.

Quizá aún más especulativa es la inferencia de AraizaMartínez (1998), que atribuye una fábrica gnéisica en rocas del Precámbrico que afloran cerca de Estación Llano, sobre la traza proyectada de la MMS, a deformación jurásica debida a la megacizalla misma. En esta región, en la mina de San Francisco, la misma deformación está asociada a metamorfismo en facies de anfibolita, por lo que es difícil pensar que toda la deformación fuese de edad jurásica. Este estudio es en realidad, un buen ejemplo de la influencia del modelo en el pensamiento geológico. No obstante, es una localidad importante porque gneises precámbricos, asignados al Grupo San Francisco, afloran en contacto tectónico con rocas volcanoclásticas con metamorfismo de bajo grado asignadas al Jurásico Medio. Como en otras localidades en el norte de Sonora, el Precámbrico cabalga sobre rocas del arco jurásico. Aunque edades de metamorfismo en la región de Altar sugieren que el principal evento de deformación en esta región es terciario inferior o Cretácico (Hayama et al., 1984), no existe evidencia de que este evento haya estado acompañado de metamorfismo en facies más altas que esquistos verdes.

3.9. Interpretación del Grupo Barranca como las facies deltaicas desplazadas del Grupo Chinle del SW de Norteamérica

Marzolf y Anderson (1996, 2000) han sugerido que el Grupo Barranca, del Triásico Superior en el centro de Sonora, fue desplazado de una posición original en el sur de Nevada. El Grupo Barranca fue interpretado como depósito de una cuenca de rift continental (e.g., Stewart y Roldán-Quintana, 1991) desarrollada sobre un orógeno Paleozoico tardío que involucró rocas de las secuencias miogeosinclinal y eugeosinclinal de Sonora. El depósito del Grupo Barranca en una cuenca alargarda delimitada por fallas normales, o una serie de cuencas con esas caracte- 
rísticas, es difícil de demostrar; además las areniscas de la secuencia son relativamente maduras con abundante cuarzo y carece de rocas volcánicas con firmas típicas de zona de rift. Aun si la Formación Santa Clara del Grupo Barranca contiene algunas arcosas inmaduras, los indicadores de paleocorrientes indican flujo hacia el sur y no son consistentes con la orientación este-oeste propuesta para un hipotético rift Barranca (Stewart y Roldán-Quintana, 1991).

Circones detríticos en areniscas de la Formación Santa Clara (Gehrels y Stewart, 1998) tienen principalmente edades de $1.42 \mathrm{Ga}$ (17 granos), 250-280 Ma (14 granos) y 225-235 Ma (3 granos). El origen de los circones en el rango de edad Pérmico-Triásico indica relativa cercanía a una fuente magmática de esa edad y una fuente probable es el arco Continental Permo-Triásico de Chihuahua, Coahuila y el noreste de México (Torres-Vargas et al., 1999; McKee et al., 1990). Los circones del Triásico pueden también provenir de localidades en el bloque Coahuila. Fuentes de esas edades en el Desierto Mojave, son escasas, aunque existen (Miller et al., 1992; Barth et al., 1997). GonzálezLeón (comunicación personal, 2005) hace notar, rocas ígneas en el rango de 240 a $288 \mathrm{Ma}$ son comunes en el sureste de California y el centro-oeste de Nevada. Plutones de edad triásica también han sido reconocidos cerca de Sonoita (Campbell y Anderson, 1998). Una prueba para la supuesta correlación de rocas del Triásico en Sonora con la secuencia triásica en Nevada sería la presencia de circones en el rango de 500 a $525 \mathrm{Ma}$, que son característicos de la Formación Osobb (Grupo Auld Lang Syne) en Nevada y también de lo que se interpreta como los drenajes continentales del Grupo Chinle de Texas a Nevada (Riggs et al., 1996). Circones de esa edad no se han reportado para la secuencia del Grupo Barranca.

3.10. Aparente truncamiento de la secuencia del arco continental Triásico-Jurásico del norte de Sonora y sur de Arizona

Anderson y Schmidt (1983) y Anderson et al. (1979) sugieren que el arco jurásico continental del norte de Sonora fue truncado por la MMS. Esta región del arco es normalmente incluida en el terreno Pápago de Haxel et al. (1984). Esta interpretación sugiere que no existen afloramientos de rocas volcánicas al sur de la traza de la MMS. Este argumento requiere revisión pues la secuencia volcánica expuesta al norte de Caborca, en los cerros la Basura y Álamo (Figura 5) contiene rocas marinas (Corona, 1979) con amonitas del Sinemuriano (García-Barragán y Jacques-Ayala, 1993), lo cual indica la presencia de una cuenca marina del Liásico al sur del arco.

En las sierras Santa Rosa, Rajón, del Álamo Muerto y Pozos de Serna, afloran secuencias marinas con faunas similares del Liásico (Hardy, 1981; Lucas et al., 1999; Stanley y González-León, 1995; Longoria y Pérez, 1979), que pueden ser correlacionables con amonitas en la se- cuencia de arco. Además de contener faunas de amonoideos y continuidad que confirma la integridad estructural de la cuenca en que se depositaron; estas secuencias se han interpretado como depósitos de cuenca de pre-arco (González-León, 1997). La secuencia está caracterizada por turbiditas y material tobáceo, aunque existen importantes variaciones laterales de facies. Localmente existen conglomerados con abundantes clastos de rocas volcánicas y granitos. Areniscas de esta secuencia (Formación Santa Rosa) tienen una petrología que sugiere fueron derivados de un arco volcánico (Stanley y González-León, 1995). Por ello, la distribución actual de rocas de arco al norte de Sonora y rocas de cuenca de prearco en la región de Caborca no requiere desplazamiento entre estos dos elementos. A esto hay que añadir que sobre el basamento del Complejo Bámuri afloran pórfidos de edades del Jurásico Medio y Tardío (Castiñeiras, comunicación personal 2004).

Otros autores han propuesto que el arco volcánico se extendía, al menos parcialmente, al sur de la traza hipotética de la falla (Jacques-Ayala, 1995). Esta interpretación se basa en que a lo largo de la traza de la MMS en Sonora afloran conglomerados del Grupo Bisbee que contienen abundantes clastos de rocas volcánicas. Indicadores de paleocorrientes sugieren fuentes al sur, en el terreno Caborca. Esto, combinado con la baja frecuencia de clastos derivados de la secuencia miogeosinclinal sugiere, como indica Jacques-Ayala (1995), que la secuencia miogeosinclinal estaba cubierta por rocas del arco volcánico.

Otra contribución importante a la controversia es la observación de una secuencia volcánica del Jurásico Medio en contacto tectónico con basamento Precámbrico en una localidad al sur de la traza de la MMS (Calmus y Sosson, 1995). Esta localidad, al norte de Puerto Peñasco, en el NW de Sonora (Figura 5), claramente demuestra que si la MMS existe, debe estar localizada al sur de esos afloramientos.

Jones et al. (1995) interpretan rocas volcánicas del centro-norte de México, en el norte de Zacatecas y Durango como un segmento desplazado del arco volcánico del norte de Sonora. Rocas volcánicas o volcanoclásticas en el centro norte de México incluyen el esquisto Caopas y la Formación Nazas (Grajales-Nishimura et al., 1992). Aunque la edad y correlación de la Formación Nazas es un problema estratigráfico complejo (Barboza-Gudiño et al., 1999), la presencia del arco volcánico triásico-jurásico en el centro de México, del sureste de Chihuahua al sur de Tamaulipas (Figura 10), está documentada por fechamientos de riolitas en el Pozo Mayran-1, Coahuila (isócrona $\mathrm{Rb}-\mathrm{Sr}$ de dos puntos con una edad de 220+/-20 Ma; Grajales-Nishimura et al., 1992), fechamientos K-Ar de intrusivos en Santa María del Oro, Durango, ca. $150 \mathrm{Ma}$ (Grajales-Nishimura et al., 1992), fechamientos U-Pb y Ar-Ar en rocas intrusivas de la sierra de las Delicias, en el valle Acatita en Coahuila, con edades ca. $215 \mathrm{Ma}$ (MolinaGarza, 2005) y una edad discordante de U-Pb en circones de un intrusivo asociado al Esquisto Caopas, en el norte de Zacatecas, de 158+/-4 Ma (Jones et al., 1995). 
La idea de que este segmento del arco haya sido desplazado por la MMS no es consistente con la edad del basamento en Durango, Zacatecas y San Luis Potosí (Rudnick y Cameron, 1991) ni con la asociación de rocas volcánicas de la Formación Nazas en Durango a secuencias continentales, no a rocas marinas del Liásico como lo es el arco volcánico en Sonora en Cerro Basura (Figura 5). Además, estas secuencias en la región del Altiplano sobreyacen rocas marinas del Triásico Superior (formaciones Zacatecas y la Ballena), mientras que en Sonora y Arizona, donde se conoce el substrato, sobreyacen secuencias del Paleozoico. Esta evidencia no es, sin embargo, contundente ya que estas relaciones pudieron resultar de los patrones de erosión anteriores a la instauración del arco.

La Formación Nazas y secuencias equivalentes en la región del Altiplano están cubiertas por la secuencia transgresiva del Oxfordiano (Formación Zuloaga y equivalentes). En la región de Caopas, Anderson et al. (1991) han identificado una deformación que asignan al Jurásico Superior. Una napa con rumbo noroeste es interpretada como resultado de tranpresión asociada a la MMS, e involucra rocas del Esquisto Caopas y la Formación Nazas. Anderson et al. (1991) también sugieren que existe deformación en la secuencia inferior de la Formación Zuloaga e interpretan la deformación como contemporánea con el depósito de esta unidad. El esquisto Caopas es difícil de correlacionar con la secuencia del arco Jurásico del norte de Sonora, ya que la edad del protolito (pórfido de cuarzo) no se conoce. Filitas en la región registran una edad de metamorfismo del Cretácico (ca. 79 Ma; Iriondo et al., 2003). Milonitas en la misma región también indican edades cretácicas aunque el espectro de argón en esas rocas está trastornado. La edad del granito mencionado anteriormente en el Esquisto Caopas es problemática, por su cercanía a la edad de depósito de la secuencia transgresiva Oxfordiana.

Por otro lado, la traza de la MMS al sur de la paleoisla de Coahuila (el arco Las Delicias), excluye afloramientos de rocas ígneas calcialcalinas como los intrusivos de la serie Acatita, en la Sierra Las Margaritas (Molina-Garza, 2005), y riolitas pre-Cretácico en la Sierra del Diablo (McKee, et al., 1990). Ambas localidades se encuentran al norte de la traza de la MMS (Figura 10).

\subsection{La existencia de cuencas transtensionales} desarrolladas sobre y al norte de la traza hipotética de la megacizalla

De acuerdo con Nourse $(1995,2001)$ cuencas del Cretácico Temprano en Sonora y el sur de Arizona registran un período de sedimentación marina que siguió a la actividad de la MMS y de una familia de fallas asociadas. Una deformación relacionada con cizalla lateral izquierda distribuida sobre una ancha región dio por resultado áreas de subsidencia definidas por afloramientos del Grupo Bisbee. De acuerdo con este autor, las márgenes de esas cuencas son fallas con orientaciones al NW y al NE que pueden ser delineadas por afloramientos del Conglomerado Glance. Por otro lado, Nourse (1995) postula que complejos de núcleo metamórfico de la región se desarrollaron preferencialmente en las áreas de la corteza que fueron adelgazadas y fracturadas por fallamiento transtensional en el Jurásico tardío-Cretácico temprano. Postula también que antes de eso, estas regiones actuaron como discontinuidades que concentraron la deformación compresional del Cretácico tardío.

McKee y Anderson (1999) han interpretado una secuencia del Cretácico Inferior cerca de Sierra Azul al norte Cucurpe (Figura 5), como depósitos de gravedad (slumping) emplazados durante el Cretácico Inferior y asociados a una cuenca con márgenes de fuerte relieve, que interpretan como una cuenca tipo "pull-apart". Aunque la cuenca está $50 \mathrm{~km}$ al norte de la traza de la MMS, estos autores sugieren que una tectónica transtensional estuvo presente en norte de Sonora y sur de Arizona. Otras cuencas para las cuales se ha postulado un origen transtensional asociado a la MMS son la cuenca McCoy, en el SW de Arizona y los depósitos de la región Altar-Santa Ana (Nourse, 2001) . De manera similar, Rodríguez-Castañeda (1994) y otros autores han sugerido que el depósito del Grupo Bisbee estuvo controlado por una tectónica transtensional asociada a la MMS en el norte de Sonora, aun si de acuerdo al modelo la MMS debe haber cesado su actividad para entonces.

La interpretación de estos depósitos como relleno de cuencas pull-apart no es simple. Por ejemplo, los afloramientos de Agua Prieta estudiados por McKee y Anderson (1999) habían sido interpretados anteriormente como una secuencia del Paleozoico cabalgando rocas del Grupo Bisbee (Rangin, 1982). Una crítica importante a los modelos que sugieren que las fallas de orientación NW-SE que afectan rocas del arco continental jurásico del norte de Sonora y sur de Arizona están asociadas a la MMS, y a los modelos que sugieren que éstas generan cuencas tipo pull-apart que acomodaron el depósito del Grupo Bisbee, es que se ha demostrado que fallas con esa orientación (e. g., falla Sawmill Canyon, en Arizona) son activas en el Cretácico Tardío y terciario temprano, afectando rocas de esa edad y produciendo rotaciones con respecto a ejes verticales (Hagstrum y Sawyer, 1989; Sosson, 1990). Uno puede argumentar que son fallas instauradas en el Jurásico Tardío, que se reactivaron en el Cretácico Superior, evidencia de corrimiento lateral jurásico como ha sido sugerido por Drewes (1996).

\subsection{El basamento de la parte norte del Altiplano}

En un estudio isotópico de andesitas de terciario medio, Cameron et al. (1989) realizaron un transecto de 700 $\mathrm{km}$ en dirección NE-SW partiendo del sur de Chihuahua, México. Los estudios isotópicos de lavas con valores relativamente bajos de $\mathrm{K} / \mathrm{P}(<7)$ y relaciones variables $\mathrm{Ba} / \mathrm{Nd}$ 
(50/18) tienen composiciones isotópicas similares, lo que sugiere que sus firmas isotópicas no están controladas por asimilación de material cortical significante. A lo largo del transecto, las rocas basálticas tienen valores de $\varepsilon \mathrm{Nd}$ y relaciones ${ }^{87} \mathrm{Sr} /{ }^{86} \mathrm{Sr}$ cerca de la composición terrestre (bulk earth) y valores de relaciones ${ }^{206} \mathrm{~Pb} /{ }^{204} \mathrm{~Pb}$ y ${ }^{207} \mathrm{~Pb} /{ }^{204} \mathrm{~Pb}$ que caen sobre la pseudoisocrona de $1.7 \mathrm{Ga}$. Este transecto cruza la traza inferida para la MMS; a la latitud del transecto, esta estructura se considera como una discontinuidad litosférica que separa basamento proterozoico al noreste, de basamento fanerozoico al suroeste. Los cambios en la geoquímica cerca de la posición inferida para la megacizalla son muy suaves, y en todo caso parecen ser más gradacionales que abruptos. La uniformidad de las composiciones isotópicas de $\mathrm{Sr}$ y $\mathrm{Nd}$ al cruzar la traza hipotética se puede interpretar de las siguientes tres maneras: (1) Las litósferas subcontinentales de los bloques Fanerozoico y Proterozoico son esencialmente indistinguibles en sus composiciones de Sr y Nd; (2) la megacizalla no es una frontera litosférica que separa cortezas del Fanerozoico y Proterozoico en la región del transecto; o, (3) las firmas isotópicas fueron adquiridas en la astenósfera y no en la litósfera subcontinental. Una conclusión similar fue ofrecida por McDowell et al. (1999). En base a un estudio del campo volcánico de Tomóchic, en la región central de Chihuahua (Figura $6)$, estos autores sugieren que una hipótesis simplista del la MMS en que ésta hubiera desplazado basamento de Laurencia no es posible.

\subsection{Datos paleomagnéticos}

Datos paleomagnéticos para el terreno Caborca fueron citados como evidencia para apoyar la hipótesis de la MMS. Estos son datos preliminares para la Formación Antimonio del Triásico y Jurásico (3 sitios) publicados por Cohen et al. (1986). Más recientemente, MolinaGarza y Geissman (1996) y Molina-Garza y Geissman (1999) publicaron datos para la Formación Antimonio, para la secuencia miogeosinclinal del NeoproterozoicoPaleozoico, en los alrededores de Caborca, y para rocas jurásicas de la secuencia llamada Fresnal Canyon del arco jurásico continental del norte de Sonora. Molina-Garza y Geissman (1999) también presentan datos para un número limitado de sitios en la secuencia Cretácico Inferior y para la serie de intrusivos laramídicos que intrusiona la secuencia miogeosinclinal.

Los datos paleomagnéticos para la Formación Antimonio y una secuencia equivalente en la Barra Los Tanques, unos $50 \mathrm{~km}$ al oeste de la localidad tipo en la sierra del Álamo (Figura 5), claramente demuestra que el estudio de Cohen et al. (1986) no se puede utilizar para probar la hipótesis de la megacizalla. En primer lugar, la magnetización característica es de origen secundario, aun si es claramente anterior al Cretácico Inferior. En segundo lugar existen complicaciones estructurales en el área de estudio que no fueron debidamente tomadas en cuenta, como el basculamiento al oeste de unidades cretácicas que sobreyacen a la secuencia triásica-jurásica. Las direcciones reportadas por Molina-Garza y Geissman (1996) se interpretan en términos de la acreción de un terreno alóctono (el terreno Antimonio) a la margen de Norteamérica o al terreno paraautóctono Caborca. La dirección observada en rocas del terreno Antimonio $\left(\mathrm{D}=186.7 .0^{\circ}, \mathrm{I}=-28.4^{\circ}\right.$; $\mathrm{n}=14$ sitios; $\mathrm{k}=28.2 ; \alpha 95=7.5^{\circ}$ ) es discordante, es decir no asemeja la dirección esperada para el intervalo JurásicoTemprano Jurásico-Tardío calculada a partir de los datos para el cratón de Norteamérica. Esta magnetización se interpreta como un registro de la acreción del terreno Antimonio al terreno Caborca en el Jurásico Tardío o como producto de la deformación de una cuenca de prearco esencialmente autóctona. La declinación de la magnetización remanente indica una rotación post- Jurásico Medio con respecto a Norteamérica, una observación común a otras áreas estudiadas en Sonora.

La dirección media observada por Molina-Garza y Geissman (1999) en la secuencia miogeosinclinal corresponde también a una magnetización secundaria probablemente adquirida en el Jurásico Medio o el Jurásico Temprano. La dirección observada $\left(\mathrm{D}=15.0^{\circ}, \mathrm{I}=10.0^{\circ} ; \mathrm{n}=28\right.$ sitios; $\mathrm{k}=23.0 ; \alpha 95=5.8^{\circ}$ ) sugiere que el terreno Caborca sufrió una rotación en el sentido horario con respecto a Norteamérica, que de acuerdo con los datos para rocas del Cretácico Inferior ocurrió en el Jurásico. Estos datos también indican que el terreno Caborca no se desplazó latitudinalmente de norte a sur (Figura 11). La secuencia jurásica volcánica Fresnal Canyon al norte de del terreno Caborca tiene una dirección $\left(\mathrm{D}=15.0^{\circ}, \mathrm{I}=4.0^{\circ} ; \mathrm{n}=10\right.$ sitios; $\mathrm{k}=12.4 ; \alpha 95=14.3^{\circ}$ ) que es esencialmente indistinguible de la dirección observada en la secuencia miogeosinclinal, indicando rotación similar en el sentido horario y sugiriendo que no existe desplazamiento relativo entre el terreno Caborca y el arco Jurásico continental. Los datos para la secuencia jurásica indican que la magnetización se adquirió antes de que cualquier deformación las afectara, lo que sugiere que se trata de una magnetización primaria. Una prueba de conglomerado (Molina-Garza y Geissman, 1998) sugiere también que la magnetización de rocas del arco volcánico en Cerro del Álamo es primaria.

La declinación media de la remagnetización regional indica una rotación en el sentido de las manecillas del reloj con respecto al cratón. Es difícil dar una interpretación tectónica a magnetizaciones secundarias a menos que el tiempo de adquisición se pueda establecer con cierta confianza. En la región de Caborca, rocas sedimentarias e intrusivas del Cretácico contienen magnetizaciones con direcciones concordantes que no indican desplazamiento con respecto a Norteamérica y las rocas más jóvenes que contienen una magnetización discordante son del Pliesbachiano (Jurásico Temprano tardío). La edad de la remagnetización regional está entonces limitada entre Jurásico Medio y Jurásico Tardío. 
Si la remagnetización regional en el terreno Caborca es del Jurásico Tardío, indicaría un desplazamiento latitudinal de sur a norte (opuesto a la hipótesis de la MMS) de aproximadamente $10^{\circ}\left(+/-7^{\circ}\right)$ y una rotación en el sentido horario de hasta $50^{\circ}$, para ambos, el arco volcánico y el terreno Caborca. Si la remagnetización observada en la secuencia miogeosinclinal es Jurásico Medio, la interpretación es más tentativa. La curva de vagabundeo polar aparente de baja latitud, propuesta por May y Butler (1986) predice paleolatitudes de $1^{\circ} \mathrm{S}$ a $14^{\circ} \mathrm{N}$ (para un sitio en el NW de Sonora) conforme Norteamérica se desplazó hacia el norte entre el Jurásico Temprano y Tardío. La curva de vagabundeo polar aparente de Van Fossen y Kent (1990) predice paleolatitudes de $1^{\circ} \mathrm{S}$ a $22^{\circ} \mathrm{N}$. La paleolatitud observada $\left(+6^{\circ} \mathrm{N}\right.$; Figura 11$)$ puede indicar desplazamiento del terreno Caborca de norte a sur, pero solamente si la magnetización es del Jurásico Medio temprano. También esta interpretación requiere que una porción del arco volcánico del norte de Sonora se haya desplazado. La observación de magnetizaciones primarias en rocas del arco volcánico al norte de Caborca (MolinaGarza y Geissman, 1998) y las edades para la secuencia volcánica cerca de Caborca (de 153 a $170 \mathrm{Ma}$; Stewart et al., 1986) sugieren que la magnetización es más bien del Jurásico Medio tardío.

En conjunto, la observación de rotaciones horarias pre-Cretácico indicada por las declinaciones al NNE, la falta de evidencia de desplazamiento latitudinal de norte a sur indicada por las inclinaciones relativamente someras y la similitud entre direcciones para localidades al norte y al sur de la traza inferida de la falla, no apoyan las reconstrucciones del terreno Caborca en posiciones al norte y al oeste de su posición actual con respecto a Norteamérica. Esto, aunado a la aparente integridad del bloque Caborca indicada por direcciones paleomagnéticas para localidades espaciadas, es quizá la evidencia más importante en contra del modelo de la MMS.

\subsection{Geología de la región del Desierto Mojave}

Rocas del Paleozoico Superior y Mesozoico Inferior en el Desierto Mojave son importantes para evaluar la hipótesis de la MMS. La traza hipotética de la megacizalla está directamente al oeste de las Montañas Soda, en la parte central del Desierto Mojave en California. Cameron (1981) fue el primero en notar la aparente continuidad de facies miogeosinclinales y cratonales del Neoproterozoico y el Paleozoico en esta región (Stewart y Poole, 1975), aparentemente invalidando esa traza para la falla. La aparente relación entre facies miogeosinclinales en el este y oeste del Desierto Mojave puede aún ser consistente con el modelo de la MMS si los afloramientos de las Montañas San Bernardino fueron transportados tectónicamente sobre la megacizalla en un tiempo posterior, pero no existe evidencia de ello.

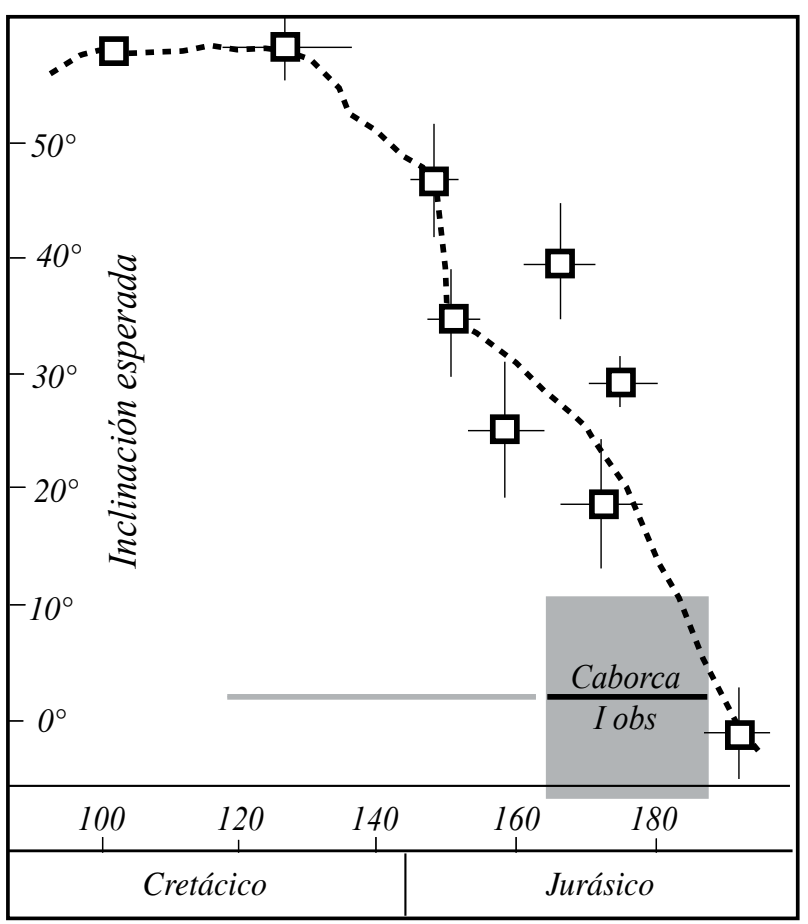

Figura 11. Inclinaciones esperadas (línea punteada) y observadas (Iobs) para el Jurásico y Cretácico en la región de Caborca, modificado de Molina-Garza y Geissman (1999).

De acuerdo al modelo de la MMS, secuencias del Paleozoico superior y el Triásico en las Montañas Soda (Figura 10) y en las regiones de los alrededores, deberían estar presentes en Sonora de haber sido desplazadas, pero rocas de esta edad en el terreno Caborca no guardan gran similitud con las del Desierto Mojave (Walker y Wardlaw, 1989). Rocas del Pérmico tardío, son escasas en Sonora y rocas del Triásico, del Grupo Barranca, son facies someras, continentales o transicionales con capas de carbón; en cambio, en el Desierto Mojave se trata de facies de agua profunda de la Formación Silver Lake del Triásico Inferior y otras unidades marinas profundas de la parte sur de la Sierra Nevada, o de rocas volcánicas subaéreas, areniscas volcanoclásticas, o cuarcitas eólicas, de la región de las Montañas Soda.

\section{Alternativas y conclusiones}

En resumen, existe evidencia que claramente contradice el modelo de la megacizalla Mojave-Sonora, como los datos paleomagnéticos (Molina-Garza y Geissman, 1999), las relaciones estratigráficas entre el arco volcánico Jurásico y una cuenca de prearco al sur de él (que no han sido suficientemente documentadas en la literatura) y la aparente imposibilidad de trazar la MMS por el Desierto Mojave. Sin embargo, no se puede ignorar la evidencia estratigráfica que liga cercanamente la secuencia miogeosinclinal de Caborca a la paleogeografía del este de California. Aun 
si estas ligas han sido recientemente cuestionadas por la continuidad aparente entre la Cuarcita Bolsa (del norte de Sonora) y la Cuarcita Proveedora de la secuencia Cámbrica de Caborca, la correlación de la secuencia de Caborca con California parece una observación sólida. La aparente imposibilidad de trazar la MMS a través del Desierto Mojave en el Paleozoico inferior sugiere que un posible desplazamiento de la secuencia miogeosinclinal ocurrió en el Paleozoico Tardío, como sugieren Walker y Wardlaw (1989) y Stone y Stevens (1988). La evidencia de una liga entre las secuencias de Nevada durante el Triásico y las secuencias del Grupo Barranca o la Formación Antimonio parecen más equívocas y probablemente requieren evaluación detallada. Otra línea de evidencia que requiere evaluarse con más detalle es la correlación del basamento de Sonora con el basamento de las provincias del este de California y sur de Arizona. Así mismo, la hipótesis de la presencia de ambientes tectónicos transtensionales en el sur de Arizona y norte de Sonora controlando el depósito del Grupo Bisbee necesita estudiarse con mayor detalle; aun si su presencia no demuestra grandes desplazamientos del terreno Caborca. La evidencia que proveen datos estratigráficos, paleomagnéticos, estructurales y geocronológicos no precluye desplazamientos de la margen pasiva miogeosinclinal SW de Norteamérica durante el Paleozoico Tardío, o incluso durante el Precámbrico antes del depósito de la secuencia miogeosinclinal.

Observaciones que apuntalan la hipótesis de un truncamiento de la margen suroeste del cratón en el Pensilvánico o Pérmico Inferior, como señalan Stevens et al. (1992), son el cambio de rumbo de la margen continental del Pensilvánico y la aparente abrupta interrupción de patrones de sedimentación en cinturones del Paleozoico Inferior. En Nevada, tanto la margen como una plataforma calcárea del Paleozoico Superior tienen un rumbo al suroeste; mientras que en el sureste de California, en la región del Desierto Mojave, el rumbo es claramente sureste. También, es evidente en el este de California una tectónica extensional (marcada subsidencia y depósitos de turbiditas) contemporánea con cabalgamientos locales, en el Pérmico inferior; esta combinación se puede atribuir a un sistema de corrimiento lateral, similar al modelo de la MMS pero más antiguo. Así, el desplazamiento de la secuencia miogeosinclinal del Neoproterozoico y Paleozoico inferior de Caborca ocurriría en el Paleozoico Tardío y no en el Jurásico (Stone y Stevens, 1988). Un modelo reciente que sigue esta línea de razonamiento fue seguido por Dickinson y Lawton (2001), quienes llaman este sistema la falla transformante California-Coahuila. De acuerdo a estos autores, el sistema California-Coahuila conectó la cinemática entre convergencia a lo largo del orógeno Sonoma en California y Nevada, y la subducción contemporánea en el este-centro de México.

Así, una evaluación objetiva de los datos estratigráficos, estructurales, geoquímicos y paleomagnéticos existentes no favorece el modelo original de desplazamiento del terreno
Caborca (y el norte de México), pero no es suficiente para desacreditar la hipótesis de la MMS de manera definitiva. El punto clave en esta evaluación es la inhabilidad de demostrar un desplazamiento latitudinal en el Jurásico Medio y Tardío, como demuestran los datos paleomagnéticos. Aunque reconstrucciones paleogeográficas para la región circum-Golfo de México requieren reposicionar partes del subcontinente Mexicano en una paleogeografía con respecto a Norteamérica distinta a la actual, el modelo de la MMS, o un sistema de fallas similares, no son la única alternativa.

\section{Agradecimientos}

Este trabajo fue apoyado por el programa PAPIITUNAM, proyecto IN-1221002 y parcialmente por el proyecto T-3286 de CONACyT. Los autores agradecen las revisiones de T. Calmus, C. González-León y T. H. Anderson, que contribuyeron de manera importante a mejorar este manuscrito.

\section{Referencias bibliográficas}

Amaya-Martínez, R. ; González-León, C., Moises, M., 1993, Las rocas volcánicas de la Formación Tarahumara y su relación con las secuencias volcanosedimentarias en la porción centro oriental del Estado de Sonora, en: González-León, C., Vega-Granillo, E.L. (eds.), III simposio de la Geología de Sonora y areas adyacentes: Instituto de Geología, Universidad Nacional Autónoma de México, 3, 1-2.

Albritton, C. C., Smith, J. F., 1957, The Texas lineament, en XX Congreso Geológico Internacional, Relaciones entre la tectónica y la sedimentación: México, D. F., International Geological Congress, 2, 501-518.

Anderson, T. H., Nourse, J. A., 1998, Releasing bends of the sinistral Late Jurassic Mojave-Sonora fault system; principal structures within the southwestern borderland of North America: Geological Society of America, Rocky Mountain Section, 50th annual meeting, Abstracts with Programs, 30, 6.

Anderson, T. H., Schmidt, V. A., 1983, The evolution of Middle America and the Gulf of Mexico-Caribbean Sea region during Mesozoic time: Geological Society of America Bulletin, 94, 941-966.

Anderson, T. H., Silver, L. T., 1977, Geochronometric and stratigraphic outlines of the Precambrian rocks of northwestern Mexico: Geological Society of America Abstracts with Programs, 9, 880.

Anderson T. H., Silver, L.T., 1979, The role of the Mojave-Sonora megashear in the tectonic evolution of northern Sonora, en: Anderson T.H. y Roldán-Quintana J. (eds.), Geology of northern Sonora: Geol. Soc. Am. Field Trip 27 Guidebook, Univ. Pittsburgh, Pennsylvania, 59-69.

Anderson, T.H., Silver, L.T., 1981, An overview of Precambrian rocks in Sonora: Revista Instituto de Geología, Universidad Nacional Autónoma de México, 5, 2, 131-139.

Anderson T.H., Eells, J., Silver, L.T., 1979, Geology of Precambrian and Paleozoic rocks, Caborca-Bamori region, en: T. H. Anderson y J. Roldán-Quintana (eds.), Geology of northern Sonora: Geological Society of America Field Trip 27 Guidebook, Univ. Pittsburgh, Pennsylvania, 1-22.

Anderson, T.H., McKee, J.W., Jones, N.W., 1991, A northwest trending, Jurassic fold nappe, northernmost Zacatecas, Mexico: Tectonics, $10,383-401$.

Araiza-Martinez, H., 1998, The San Francisco gold mine municipality of Santa Ana, Sonora, Mexico, en: Clark, K. F. (ed.): Gold deposits of 
northern Sonora, México, Guidebook Series - Society of Economic Geologists, 30, 49-58.

Barboza-Gudiño, J.R., Tristán-González, M., Torres Hernández, J.R., 1999, Tectonic setting of pre-Oxfordian units from central and northeastern Mexico: A review, in: Mesozoic sedimentary and tectonic history of north-central Mexico, en: Bartolini, C., Wilson, J.L., Lawton, T.F. (eds.), Mesozoic sedimentary and tectonic history of north-central Mexico: Geological Society of America Special Paper, 340, 197-210.

Barth, A.P., Tosdal, R.M., Wooden, J L., Howard, K.A., 1997, Triassic plutonism in Southern California; southward younging of arc initiation along a truncated continental margin: Tectonics, 16, 290-304.

Brunner, P., 1976, Litología y biostratigrafía del Misisípico en el área E1 Bisani, Caborca, Sonora: Revista Instituto Mexicano del Petróleo, $8,7-41$.

Calmus, T., Sosson, M., 1995, Southwestern extension of the Papago terrane into the Altar Desert region, northwestern Sonora, and its implications, en: Jacques-Ayala C., González-León, CM., y Roldán-Quintana, J., (eds.), Studies on the Mesozoic of Sonora and adjacent areas: Geological Society of America Special Paper, 301, 99-110.

Calmus, T., Pérez-Segura, E., Stinnesbeck, W., 1997, La structuration de la marge pacifique nord-américaine et du "terrane Caborca": apports de la découverte d'une faune du Jurassique inférieur et moyen dans la série de Pozos de Serna (Sonora, Mexique); Comptes Rendus de l'Academie des Sciences, t. 323, série IIa, 795-800.

Cameron, C.S., 1981, Geology of the Sugarloaf and Delamar mountain areas, San Bernardino Mountains, California, unpublished Ph.D. Dissertation: Massachusetts Institute of Technology, Cambridge, Massachusetts, $399 \mathrm{p}$.

Cameron, K. L., Nimz, G. J., Kuentz, D., Niemeyer, S., Gunn, S., 1989, Southern Cordilleran basaltic andesite suite, southern Chihuahua, Mexico; a link between Tertiary continental arc and flood basalt magmatism in North America: Journal of Geophysical Research, 94, B6, 7817-7840.

Campa, M.F., Coney, P.J., 1983, Tectonostratigraphic terranes and mineral resource distribution in Mexico: Canadian Journal of Earth Sciences, 20, 1040-1051.

Campbell, P. A., Anderson, T. H., 1998, Structure and kinematics along a Jurassic Plate Boundary Transform, the Mojave-Sonora Megashear, en: Clark, K.F., (ed.), Gold Deposits of northern Sonora, Mexico: Society of Economic Geologists, Guidebook Series, Fort Collins CO, 30, 177-186.

Campbell, P. A., Anderson, T. H., 2003, Structure and kinematics along a segment of the Mojave-Sonora megashear: A strike-slip fault that truncates the Jurassic continental magmatic arc of southwestern North America (DOI 10.1029/2002TC001367): Tectonics, 22(6), 16.

Caudillo-Sosa, G., Oviedo-Lucero, L.F., Rodríguez-Castañeda, J.L., 1996, Falla Quitovac - Resultado de un evento de transpresión del "Mojava-Sonora megashear", noroeste de Sonora, México: Revista Mexicana de Ciencias Geológicas, 13, 2, 140-151.

Clark, K. F., 1998, Gold deposits of northwestern Sonora, Mexico: Society of Economic Geologists, Fort Collins, CO., Guidebook Series, 30, $252 \mathrm{p}$.

Charleston, S., 1981, Lower Cretaceous stratigraphy and structure, northern Mexico; field trip guidebook, West Texas Geological Society, Midland, TX, 81-74.

Chávez-Cabello G., Aranda-Gómez, J. J., Molina-Garza, R. S., CossíoTorres, T., Arvizu-Gutiérrez, I. R., González-Naranjo, G., 2005, La Falla San Marcos: Una estructura jurásica de basamento multireactivada del noreste de México, Boletín de la Sociedad Geológica Mexicana (este volumen).

Cohen, K. K., Anderson, T.H., Schmidt, V. A., 1986, A paleomagnetic test of the proposed Mojave-Sonora megashear in northwest Sonora, Mexico: Tectonophysics, 131, 23-51.

Conway, C. M., Silver, L.T., 1989, Early Proterozoic rocks (1710-1615) in central and southeastern Arizona, en: Jeney, J. P., Reynolds, S. J., (eds.), Geologic evolution of Arizona: Arizona Geological Digest, 17, 211-238.
Cooper, G. A., Arellano, A. R.V., 1946, Stratigraphy near Caborca, northwest Sonora, Mexico: American Association of Petroleum Geologists Bulletin, 30, 4, 606-610.

Cooper, G. S., Okulich, V. J., Stoyanow, A., Villabos-Figueroa A., Arellano, A. R. V., Johnson, J. H., Lochman-Balk, C., 1952, Cambrian stratigraphy and paleontology near Caborca, northwestern Sonora, Mexico, Smithsonian Miscellaneous Collections, 119(1), 183 p.

Corona, F. V., 1979, Preliminary reconnaissance geology of Sierra La Gloria and Cerro Basura, northwestern Sonora, Mexico; en: T.H. Anderson y J. Roldán-Quintana (eds.), Geology of northern Sonora: Geological Society of America Field Trip 27 Guidebook, 59-69, Univ. Pittsburgh, Pennsylvania.

Damon, P. E., Livingston, D. E., Mauger, R. L., Gilletti, B. J., Alor, P. , 1962, Edad del Precámbrico Anterior y de otras rocas del zócalo de la región de Caborca-Altar de la parte noroccidental del Estado de Sonora: Boletín Instituto de Geología, Universidad Nacional Autónoma de México, 64, 11-64.

Damon, P. E., Shafiqullah, M., Roldán-Quintana, J., Jacques-Ayala, C., 1983, El batolito Laramide (90-40 Ma) de Sonora: Asociación Ingenieros de Minas, Metalurgistas y Geólogos de México, Memoria Técnica, XV, 63-96.

Drewes, H., 1996, A ramp-end strike-slip fault near Paradise, Chiricahua Mountains, southeastern Arizona: Geological Society of America Abstracts with Programs, 28, 63.

De Cserna, Z., 1971, Development and structure of the Sierra Madre Oriental of Mexico: Geological Society of America Abstracts with Programs, 3(6), 377-378.

De Cserna, Z. , 1976, Mexico; geotectonics and mineral deposits: New Mexico Geological Society Special Publication, 6, 18-25.

De Jong, K.A., Escárcega, J.A., Damon, P.E. , 1988, Eastward thrusting, southwestward folding, and westward back-sliding in the Sierra de Víbora, Sonora, Mexico: Geology, 16, 904-907.

Dickinson, W.R., Lawton, T. F., 2001, Carboniferous to Cretaceous assembly and fragmentation of Mexico: Geological Society of America Bulletin, 113, 1142-1160.

Eells, J. L., 1972, Geology of the Sierra de la Berruga, northwestern Sonora, Mexico, tesis de maestría, San Diego State University, $77 \mathrm{p}$.

García-Barragán, J. C., Jacques-Ayala, C., 1993, Stratigraphy and depositional setting of a red conglomerate in the Cerro la Gloria, Caborca, Sonora, en: González-León, C., Vega-Granillo, E. L. (eds.), III simposio de la Geologia de Sonora y areas adyacentes: Instituto de Geología, Universidad Nacional Autónoma de México, 3, 33-34.

García y Barragan, J. C. , Jacques-Ayala, C. J. , DeJong, K. A. , 1998, Stratigraphy of the Cerros El Amol, Altar, Sonora, México, en: Clark, K. F. (ed.), Gold deposits of northern Sonora, México: Guidebook Series - Society of Economic Geologists, 30, 101-116.

Gehrels, G. E., Stewart, J. H. , 1998, Detrital zircon U-Pb geochronology of Cambrian to Triassic miogeosinclinal and eugeosinclinal strata of Sonora, Mexico: Journal of Geophysical Research, B, Solid Earth and Planets, 103(2), 2471-2487.

Gómez-Luna, M.E., Martínez-Cortés, A.M. , 1997, Relaciones y diferencias de la sucesión de amonoideos Triásicos del noroeste de Sonora y de Nevada centro-oeste, en: González-León, C., y Stanley, G. (eds.), Publicaciones Ocasionales Estación Regional del Noroeste: Instituto de Geología, Universidad Nacional Autónoma de México, 1, 19-22.

González-León, C.M., 1997, Sequence stratigraphy and paleogeographic setting of the Antimonio Formación (Late Permian-Early Jurassic), Sonora, México: Revista Mexicana de Ciencias Geológicas, 14, 136-148.

González-León, C.M., 1980, La Formación Antimonio (Triásico SuperiorJurásico Inferior) en la Sierra del Alamo, Estado de Sonora: Revista Intituto de Geología, Universidad Nacional Autónoma de México, 4, 13-18.

González-León, C., Stanley, G. D. Jr., 1993, The Antimonio Terrane of western Sonora and its paleogeographic significance, en: GonzálezLeon, C., Vega-Granillo, E. L. (eds.), III simposio de la Geología de Sonora y áreas adyacentes: Instituto de Geología, Universidad 
Nacional Autónoma de México, 3, 41-43.

González-León, C.M., Lawton, T.F., 1995, Stratigraphy, depositional environments and origin of the Cabullona basin, northwestern Sonora, en: Jacques-Ayala C., González-león, CM., Roldán-Quintana, J., (eds.): Studies on the Mesozoic of Sonora and adjacent areas, Geological Society of America Special Paper, 301, 121-143.

González-León, C.M., Lucas, S.G., 1995, Stratigraphy and paleontology of the Early Cretaceous Cerro de Oro Formación, central Sonora, en: Jacques-Ayala C., González-León, C. M., Roldán-Quintana, J., (eds.), Studies on the Mesozoic of Sonora and adjacent areas: Geological Society of America Special Paper, 301, 41-48.

González-León, C.M., Taylor, D.G., Stanley, G.D. Jr., 1996, The Antimonio Formation in Sonora, Mexico, and the Triassic-Jurassic boundary: Canadian Journal of Earth Sciences, 33, 418-428

Grajales-Nishimura, J.M., Terrell, D.J., Damon, P.E. , 1992, Evidencias de la prolongación del arco magmático Cordillerano del Triásico Tardío-Jurásico en Chihuahua, Durango y Coahuila: Boletín Asociación Mexicana de Geólogos Petroleros, XLII, 1-18.

Hagstrum, J. T., Sawyer, D.A., , 1989, Late Cretaceous paleomagnetism and clockwise rotation of the Silver Bell Mountains, south central Arizona: Journal of Geophysical Research, B, Solid Earth and Planets, 94, 12, 17847-17860.

Hardy, L.R., 1981, Geology of the central Sierra de Santa Rosa, northwest Sonora, Mexico, en: Ortlieb, L., y Roldán-Quintana, J., (eds.), Geology of northwestern Mexico and southern Arizona: Geological Society of America, Cordilleran Section Annual Meeting, Field Guides and Papers, 73-98.

Haxel, G.B., Tosdal, R.M., May, D.J., Wright, J.E. , 1984, Latest Cretaceous and early Tertiary orogenesis in south-central Arizona: Thrust faulting, regional metamorphism, and granitic plutonism: Geological Society of America Bulletin, 95, 631-653.

Hayama, Y., Shibata, K., Takeda, H. , 1984, K-Ar ages of the low-grade metamorphic rocks in the Altar massif, northwest Sonora, Mexico: Journal of the Geological Society of Japan, 90, 586-596.

Henry, C. D., Aranda-Gomez, J. J., 2000, Plate interactions control middle-late Miocene, proto-Gulf and Basin and Range extension in the southern Basin and Range, en: The influence of plate interaction on post-Laramide magmatism and tectonics in Mexico: Tectonophysics, 318(1-4), 1-26.

Iriondo, A., 2001, Proterozoic basements and their laramide juxtaposition in NW Sonora, Mexico: Tectonic constraints on the SW margin of Laurentia, tesis doctoral, University of Colorado, Boulder, 222 p.

Iriondo, A., Atkinson, W.W., 2000, Orogenic gold mineralization along the proposed trace of the Mojave-Sonora megashear: Evidence for the Laramide Orogeny in NW Sonora, Mexico: Geological Society of America Abstracts with Programs, 32, 393.

Iriondo, A., Kunk, M.J., Winick, J.A., y CRM, 2003, 40Ar/39Ar dating studies of minerals and rocks in various areas in Mexico: USGS/ CRM Scientific Collaboration Part I, U. S. Department of Interior, U. S. Geological Survey, Open File Report, 03-020, 79 p.

Iriondo, A., Premo, W. R., 2003, The Caborca Block; an inhomogeneous piece of Paleoproterozoic crust in Sonora: Geological Society of America, Cordilleran Section, 99th annual meeting, Abstracts with Programs, 35(4), 67.

Iriondo, A., Premo, W.R., Martínez-Torres, L.M., , Budahn, J.R., Atkinson, W.W.Jr., Siems, D.F., Guaras-González, B., 2004, Isotopic, geochemical, and temporal characterization of Proterozoic basement rocks in the Quitovac region, northwestern Sonora, México: Implications for the reconstruction of the southwestern margin of Laurentia: Geological Society of America Bulletin, 116, 154-170.

Jacques-Ayala, C., 1995, Geology and provenance of Lower Cretaceous Bisbee Group in the Caborca-Santa Ana area, northwest Sonora, en: Jacques-Ayala C., González-León, C.M., y Roldán-Quintana, J., (eds.), Studies on the Mesozoic of Sonora and adjacent areas: Geological Society of America Special Paper, 301, 79-98.

Jacques-Ayala, C., Clark, K.F., 1998, Lithology, structure and gold deposits of northwestern Sonora, Mexico, Gold deposits of northern Sonora, Mexico, en: Clark, K.F., (ed.), Gold Deposits of northern Sonora, Mexico: Society of Economic Geologists - Guidebook Series, 30, 203-234.
Jacques-Ayala, C., De Jong, K.A. , 1996, Extension of the Orocopia Schist belt into northwestern Sonora, Mexico: A working hypothesis, Geological Society of America Abstracts with Programs, 28(5), 78.

Jacques-Ayala, C., García-Barragán, J.C., De Jong, K.A., 1990, CaborcaAltar Geology: Cretaceous sedimentation and compression, Tertiary uplift and extension, Arizona Geological Survey Special Paper, 7 , 165-182.

Jones, N.W., McKee, J.W., Anderson, T.H., Silver, L.T. , 1995, Jurassic volcanic rocks in northeastern Mexico: A possible remnant of a Cordilleran magmatic arc, en: Jacques-Ayala C., González-león, CM., Roldán-Quintana, J., (eds.), Studies on the Mesozoic of Sonora and adjacent areas: Geological Society of America Special Paper, 301, 179-190.

Karlstrom, K. E., Williams, M. L., 1995, The case for simultaneous deformación, metamorphism and plutonism; an example from Proterozoic rocks in central Arizona: Journal of Structural Geology, $17,59-81$.

Ketner, K.B., 1986, Eureka quartzite in Mexico? - Tectonic implications, Geology, 14, 1027-1030.

Ketner, K.B., Noll, J.H. , 1987, Preliminary geologic map of the Cerro Cobachi area, Sonra, Mexico: U.S. Geological Survey Misc, Field Studies Map, MF-1980.

Krieger, M.H. , 1961, Troy Quartzite (younger Precambrian) and Bolsa and Abrigo Formations (Cambrian), northern Galiuro Mountains, southeastern Arizona: Article 207, U. S. Geological Survey Professional Paper, C160-C164.

Kurtz, J.R., Gehrels, G.E., Stewart, J.H., 1988, Detrital zircons geochronology of the Bolsa Quartzite (Cambrian) in Sonora, Mexico: Geolological Society of America Abstracts with Programs, 30, $5,49$.

Leveille, G. P., Frost, E.G. , 1984, Deformed upper Paleozoic-lower Mesozoic cratonic strata, El Capitan, Sonora, Mexico: Geological Society of America, 97th annual meeting, Abstracts with Programs, $16,6,575$.

Longoria, J.F., Pérez, V.A., 1979, Bosquejo geológico de los Cerros Chino y Rajón, cuadrángulo Pitiquito-La Primavera (NW de Sonora): Universidad de Sonora, Boletín Departamento de Geología, 1(2), 119-144.

Lottes, A. L., Rowley, D. B., 1990, Early and Late Permian reconstructions of Pangaea, Palaeozoic palaeogeography and biogeography: Geological Society of London, Memoir 12 , 383-395.

Lucas, S.G., Estep, J.W., 1999, Permian, Triassic, and Jurassic stratigraphy, biostratigraphy and sequence stratigraphy in the Sierra del Alamo Muerto, Sonora, Mexico, en: Bartolini, C., Wilson, J.L., Lawton, T.F. (eds.), Mesozoic sedimentary and tectonic history of north-central Mexico: Geological Society of America Special Paper, 340, 271-286.

Lucas, S.G., Estep, J.W., Molina-Garza, R.S., 1999, Early Jurassic ammonites at Cerro Pozos de Serna, Sonora, Mexico, N. Jb. Geol. Paläont. Mh., 6, 357-371.

Lucas, S. G., González-León, C. M. , 1994, Marine Upper Triassic strata at Sierra la Flojera, Sonora, México: N. Jb. Geol. Palaont. Mh., H-1, 34-40.

Marzolf, J. E., Anderson, T. H. , 1996, Early Mesozoic paleogeography and the Mojave Sonora Megashear: Geological Society of America, 28th Annual meeting, Abstracts with Programs, 28(7), 114.

Marzolf, J. E., Anderson, T. H. , 2000, Restoration of the Caborca Block; alternative models: Geological Society of America, 2000 annual meeting, Abstracts with Programs, 32(7), 46.

May, S.R., Butler, R.F. , 1986, North American Jurassic apparent polar wander: Implications for plate motion, paleogeography and cordilleran tectonics: Journal Geophys. Res., 91, 11519-11544.

McKee, J. W., Jones, N. W., Long, Leon E., 1984, History of recurrent activity along a major fault in northeastern Mexico: Geology, 12(2), 103-107.

McKee, J.W., Jones, N.W., Long, L.E., 1990, Stratigraphy and provenance of strata along the San Marcos fault, central Coahuila, Mexico: Geological Society of America Bulletin, 102, 593-614.

McKee, J.W., Anderson, T.H., 1999, Mass-gravity deposits and structures 
in the Lower Cretaceous of Sonora, Mexico: Geological Society of America Bulletin, 110(12), 1516-1529.

McDowell, F.W., Housh, T.B., Wark, D.A., 1999, Nature of the crust beneath west-central Chihuahua, Mexico, based upon $\mathrm{Sr}, \mathrm{Nd}$, and $\mathrm{Pb}$ isotopic compositions at the Tomóchic volcanic center: Geological Society of America Bulletin, 111(6), 823-830.

Merriam, R., 1972, Reconnaissance geologic map of the Sonoita quadrangle, northwest Sonora, Mexico: Geological Society of America Bulletin, 95, 631-653.

Merriam, R., Eells, J.L. , 1979, Reconnaissance geologic map of the Caborca quadrangle, Sonora, Mexico, Boletín Departamento de Geología, Uni-Son, 1, 2, 87-94.

Miller, C. F., Wooden, J. L., Gerber, M. E. , 1992, Plutonism at a tectonically evolving continent margin; Mesozoic granitoids of the eastern Mojave Desert, California, USA: 29th International Geological Congress; Abstracts, 29, 519.

Mitre-Salazar, L.M., 1989, La megafalla laramídica de San Tiburcio, Estado de Zacatecas: Revista Instituto de Geología, Universidad Nacional Autónoma de México, 8, 47-51.

Molina-Garza, R.S., 2005, Paleomagnetic data for the Late Triassic Acatita intrusives, Coahuila, Mexico: Tectonic implications, Geofísica Internacional, 44, 197-210.

Molina-Garza R.S., Geissman, J.W., 1996, Timing of deFormación and accretion of the Antimonio terrane, Sonora, from paleomagnetic data: Geology, 24, 1131-1134.

Molina Garza, R.S., Geissman, J.W., 1998, Paleomagnetic evidence against Jurassic left-lateral (southeastward) displacement of the Caborca Terrane, en: Clark, K.F. (ed.), Gold deposits of northern Sonora, Mexico: Guidebook Series - Society of Economic Geologists, 30, 187-201.

Molina Garza R.S., Geissman, J.W., 1999, Paleomagnetic data from the Caborca terrane, Mexico: Implications for Cordillera tectonics and the Mojave-Sonora megashear:Tectonics, 18, 293-325.

Muller, S., Ferguson, W., Gardiner, H., 1936, Triassic and Jurassic Formations of west-central Nevada: Geological Society of America Bulletin, 47(2), 241-251.

Nourse, J.A. , 1990, Tectonostratigraphic development and strain history of the Magdalena metamorphic core complex, northern Sonora, Mexico: Arizona Geological Survey Special Paper, 7, 155-164.

Nourse, J.A., 1995, Jurassic-Cretaceous paleogeography of the Magdalena region, northern Sonora, and its influence on the positioning of Tertiary metamorphic core complexes, en: Jacques-Ayala, C., González-León, C. M., Roldán-Quintana, J. (eds.), Studies on the Mesozoic of Sonora and adjacent areas: Geological Society of America Special Paper, 301, 59-78.

Nourse, J.A., 2001, Tectonic Insights From an Upper Jurassic-Lower CretaceousStretched-Clast Conglomerate, Caborca-Altar Region, Sonora, Mexico: Journal of South American Earth Sciences, 14(5), 453-474

Oldow, J.S., 1984, Evolution of a late Mesozoic back-arc fold and thrust belt, northwestern Great: Tectonophysics, 102(1-4), 245-274.

Oldow, J.S., Satterfield, J. I.; Silberling, N. J., 1993, Jurassic to Cretaceous transpressional deformación in the Mesozoic marine province of the northwestern Great Basin, en: Lahren, M.M., Trexler, J.H., Jr., Spinosa, C. (eds.), Crustal evolution of the Great Basin and the Sierra Nevada, University of Nevada, Reno, 129-166.

Padilla y Sánchez, R.J., 1986, Post-Paleozoic tectonics of northeast Mexico and its role in the evolution of the Gulf of Mexico: Geofisica Internacional, 25, 157-206.

Pilger, R.H. , 1978, A closed gulf of Mexico, pre-Atlantic Ocean plate reconstructions and the early rift history of the Gulf and North Atlantic: Gulf Coast Association of Geological Societies Transactions, 28, 383-393.

Pindell, J., Dewey, J. F. , 1982, Permo-Triassic reconstruction of western Pangea and the evolution of the Gulf of Mexico/Caribbean region: Tectonics, 1(2), 179-211.

Poole, F.G., Madrid, R.J. , 1988, Allochthonous Paleozoic eugeosinclinal rocks of Barita, Sonora mine area, central Sonora, Mexico, en: Rodríguez, T. (ed.), Libreto Guía Excursión Geológica, II Simposio sobre Geología y Minerales del Estado de Sonora, Excursión de
Campo, Instituto de Geología, Universidad Nacional Autónoma de México y Universidad de Sonora, Hermosillo, Sonora, 32-41.

Poole, F.G., Amaya-Martínez, R., Page, W.R., 2000, Silurian and Devonian carbonate shelf rocks and Lower Jurassic sequence near Rancho Placeritos, west-central Sonora: Field Guide for Field Trip 2, IV Symposium on the geology of northwest Mexico and adjacent areas, Center for the Arts, Universidad de Sonora, Hermosillo, México, $24 \mathrm{p}$.

Poole, F.G., Perry, W.J., Madrid, R.J., Amaya-Martínez, R., 2004, Tectonic synthesis of the Ouachita-Marathon-Sonora orogenic margin of southern Laurentia: Stratigraphic and structural implications for timing of deformational events and plate tectonic models, Geological Society of America Special Paper, in press.

Pubellier, M., Rangin, C., Rascon, B., Chorowicz, J, Bellon, H., 1995, Cenomanian thrust tectonics in the Sahuaria region, Sonora; implications about northwestern Mexico megashears, en: Jacques-Ayala, C., González-León, C.M., Roldán-Quintana, J. (eds.), Studies on the Mesozoic of Sonora and adjacent areas: Geological Society of America Special Paper, 301, 111-120.

Riggs, N.R., Lehman, T.M., Geherels, G.E., Dickinson, W.R. , 1996, Detrital zircon link between headwaters and terminous of the Upper Triassic Chinle-Dockum paleoriver system, Science, 273, 97-100.

Rodríguez-Castañeda, J.L., 1984, Geology of Tuape region, north-central Sonora, Mexico, Pittsburgh, PA, University of Pittsburgh, tesis de maestría, $157 \mathrm{p}$.

Rodríguez-Castañeda, J.L., 1994, Geología del área El Teguchi, Estado de Sonora, México: Revista Mexicana de Ciencias Geológicas, $11(1), 11-28$.

Rodríguez-Castañeda, J.L., 1996 Late Jurassic and mid-Tertiary brittleductile deformación in the Odepe region, Sonora, México: Revista Mexicana de Ciencias Geológicas, 13(1), 1-9.

Rudnick, R. L., Cameron, K. L., 1991, Age diversity of the deep crust in northern Mexico; with Suppl. Data 91-34: Geology, 19(12), 1197-1200.

Sedlock, R.L., Ortega-Gutiérrez, F., Speed, R.C., 1993, Tectonostratigraphic terranes and tectonic evolution of Mexico: Geological Society of America Special Paper, 278, 153 p.

Silberling, N. J., Tozer, E. T., 1968, Biostratigraphic classification of the marine Triassic in North America, Geological Society of America Special Paper, $110 \mathrm{p}$.

Silver, L.T., 1965, Mazatzal orogeny and tectonic episodicity: Geological Society of America Special Paper, 82, 185-186.

Silver, L.T., Anderson, T.H. , 1974, Possible left-lateral early to middle Mesozoic disruption of the southwestern North America craton margin: Geological Society of America Abstracts and Programs, 6, 955-956.

Sosson, M., 1990, Le passage des Cordilléres nord-américaines aux Sierras Madres mexicaines, sud de l'Arizona (Etats-Unis) et nor du Sonora (Mexique), Tesis de habilitación, Universidad de NizaSophia Antipolis, Niza, Francia, 428 p.

Stanley, G. D., González-León, C., 1995, Paleogeographic and tectonic implications of Triassic fossils and strata from the Antimonio Formación, northwestern Sonora, en: Jacques-Ayala C. GonzálezLeón C., y Roldán-Quintana, J., (eds.), Studies of the Mesozoic of Sonora and Adjacent Regions, Geological Society of America Special Paper, 301, 1-16.

Stevens, C.H., Stone, P., Kistler, R.W. , 1992, A speculative reconstruction of the middle Paleozoic continental margin of southwestern North America: Tectonics, 11, 405-419.

Stevens, C.H., Stone, P., 1988, Early Permian thrust faults in eastcentral California: Geological Society of America Bulletin, 100, $552-562$.

Stewart, J. H., 2003, Mojave-Sonora megashear; evidence from Neoproterozoic to Lower Jurassic strata: Geological Society of America, Cordilleran Section, 99th annual meeting, Abstracts with Programs, 35(4), 13.

Stewart, J.H., Poole, F.G. , 1975, Extension of the Cordilleran miogeocline belt to the San Andreas fault, southern California: Geological Society of America Bulletin, 86, 205-212. 
Stewart, J.H., Roldán-Quintana, J. , 1991, Upper Triassic Barranca Group: Nonmarine and shallow-marine rift-basin deposits of northwestern Mexico, en: Pérez-Segura, E., y Jacques-Ayala, C., (eds.), Studies of Sonoran Geology: Geological Society of America Special Paper, 254, 19-35.

Stewart, J.H., McMenamin, A.S., y Morales-Ramírez, J.M. , 1984, Upper Proterozoic and Cambrian rocks in the Caborca region, Sonora, México - Physical stratigraphy, Biostratigraphy, Paleocurrent studies, and Regional Relations: U. S. Geological Survey Professional Paper, 1309, $32 \mathrm{p}$.

Stewart, J. H., Anderson, T.H., Haxel, G.B., Silver, L.T., Wright, J.E., 1986, Late Triassic paleogeography of the southern Cordillera: the problem of a source for voluminous volcanic detritus in the Chinle Formation of the Colorado Plateau region: Geology, 14, 567-570.

Stewart, J.H., Poole, F.G., Ketner, K.B., Madrid, R.J., Roldán-Quintana, J., Amaya-Martínez, R., 1990, Tectonics and Stratigraphy of the Paleozoic and Triassic southern margin of North America, Sonora, Mexico, en: Gehrels, G.E., Spencer, J.E. (eds.), Geologic excursions through the Sonoran Desert region, Arizona and Sonora: Arizona Geological Society, Special Paper, 7, 183-202.

Stewart, J.H., Amaya-Martínez, R., Stamm, R.H., 1997, Stratigraphy and regional significance of Mississippian to Jurassic rocks in Sierra Santa Teresa, Sonora, México: Revista Mexicana de Ciencias Geológicas, 14, 115-135.

Stewart, J. H., Poole, F. G., Harris, A. G., Repetski, J. E.,Wardlaw, B. R., Mamet, B. L., Morales-Ramirez, J. M., 1999, Neoproterozoic(?) to Pennsylvanian inner-shelf, miogeosinclinal strata in Sierra Agua Verde, Sonora, México: Revista Mexicana de Ciencias Geológicas, 16(1), 35-62.

Stewart, J. H., Amaya-Martínez, R. Palmer, A. R. , 2002, Neoproterozoic and Cambrian strata of Sonora, Mexico; Rodinian supercontinent to Laurentian Cordilleran margin, en: Contributions to crustal evolution of the Southwestern United States: Geological Society of America Special Paper, 365, 5-48.

Stone, P., Stevens, C.H., 1988, Pennsylvannian and Early Permian paleogeography of east-central California: Implications for the shape of the continental margin and the timing of continental truncation: Geology, 16, 330-333.

Strickland, J. M., Middleton, L.Y., 2000, Sedimentology, stratigraphy and paleogeographical implications of the Cambrian Bolsa Quartztite and Abrigo Formación, southeastern Arizona: Geological Society of America, Abstracts with Programs, 32, 308-309.
Torres-Vargas, R., Ruiz, J., Patchett, P. J., Grajales-Nishimura, M., 1999, Permo-Triassic continental arc in eastern Mexico; tectonic implications for reconstructions of southern North America, en: Mesozoic sedimentary and tectonic history of north-central Mexico: Geological Society of America Special Paper, 340, 191-196.

Tosdal, R. M., Haxel, G. B, Wright, J. E., 1989, Jurassic geology of the Sonoran Desert region, southern Arizona, southeastern California, and northernmost Sonora: Construction of a continental-margin magmatic arc, en: Jenney, J. P., Reynolds, S. J., (eds.), Geologic Evolution of Arizona: Arizona Geological Society Digest, 17, 397-434.

Tozer, E. T. , 1980, New genera of Triassic Ammonoidea: Current Research, Part A, Paper - Geological Survey of Canada, 80-1A, 107-113.

Valencia-Moreno, M., Ruiz, J., Roldán-Quintana, J., 1999, Geochemistry of Laramide granitic rocks across the southern margin of the Paleozoic North American Continent, central Sonora, Mexico: International Geology Review, 41, 845-857.

Van Fossen, M.C., Kent, D.V., 1990, High latitude paleomagnetic poles from Middle Jurassic plutons and Moat Volcanics in New England and the controversy regarding Jurassic apparent polar wander for North America: Journal Geophysical Research, 95, 17503-17516.

Walker, J.D., 1988, Permian and Triassic rocks of the Mojave Desert and their implications for timing and mechanisms of continental truncation: Tectonics, 7, 685-709.

Walker, J. D. Wardlaw, B.R., 1989, Implications of Paleozoic and Mesozoic rocks in the Soda Mountains, northeastern Mojave Desert, California, for late Paleozoic and Mesozoic Cordilleran orogenesis: Geological Society of America Bulletin, 101, 1574-1583.

Manuscrito recibido: Octubre 10, 2004

Manuscrito corregido recibido: Enero 8, 2005

Manuscrito aceptado: Enero 10, 2005 